\title{
Selected Hydrologic Data from Fortymile Wash in the Yucca Mountain Area, Nevada, Water Year 1992
}

\section{by Charles S. Savard}

\section{U.S. GEOLOGICAL SURVEY}

Open-File Report 94-317

Prepared in cooperation with the

U.S. DEPARTMENT OF ENERGY under

Interagency Agreement DE-Al08-92NV10874

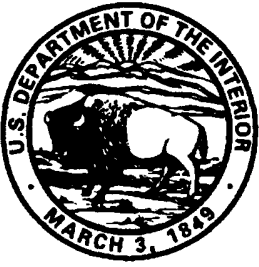




\section{U.S. DEPARTMENT OF THE INTERIOR \\ BRUCE BABBITT, Secretary}

U.S. GEOLOGICAL SURVEY

Gordon P. Eaton, Director

The use of trade, product, industry, or firm names is for descriptive purposes only and does not imply endorsement by the U.S. Government.

For additional information write to:

Chief, Earth Science Investigations Program

Yucca Mountain Project Branch

U.S. Geological Survey

Box 25046, MS 421

Denver Federal Center

Denver, CO 80225
Copies of this report can be purchased from:

U.S. Geological Survey

Earth Science Information Center

Open-File Reports Section

Box 25286, MS 517

Denver Federal Center

Denver, CO 80225 


\section{CONTENTS}

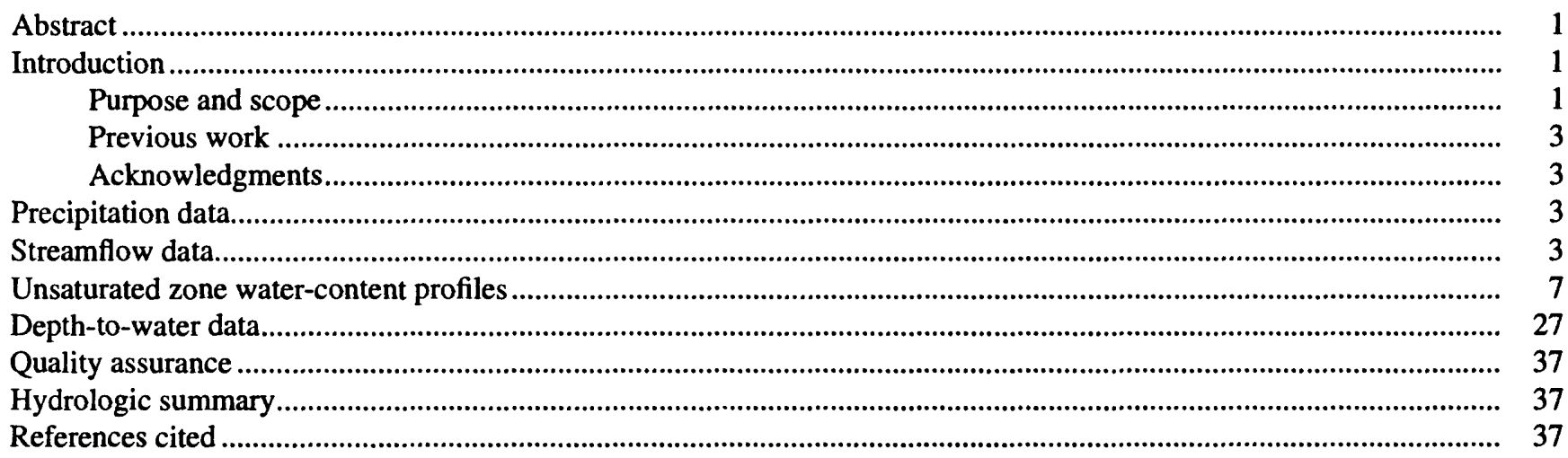

\section{FIGURES}

1. Map showing location of gaging stations, crest-stage gages, neutron-access boreholes, and wells .................... 2

2. Graph showing cumulative precipitation at UE-29 UZN \#91 and UE-29 UZN \#92 .......................................... 5

3-5. Photographs showing:

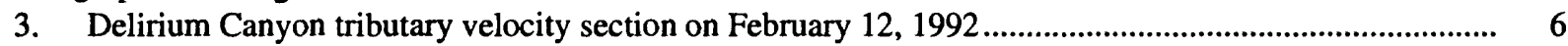

4. Delirum Canyon tributary velocity section on February 13, 1992 ................................................... 6

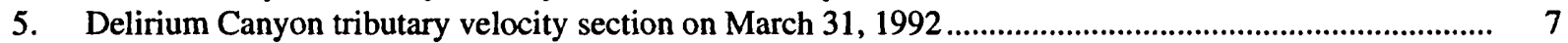

6-10. Graphs showing preliminary volumetric water content for UE-29 UZN \#91 for:

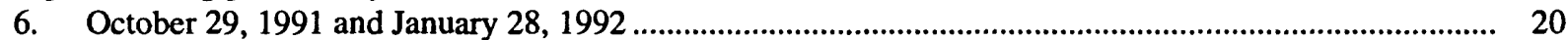

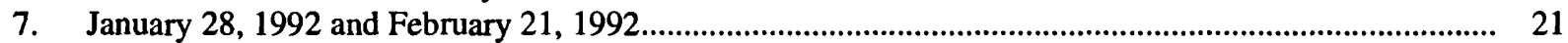

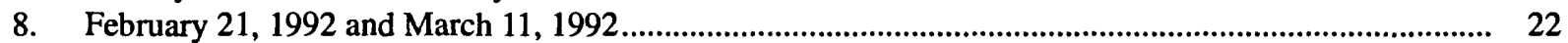

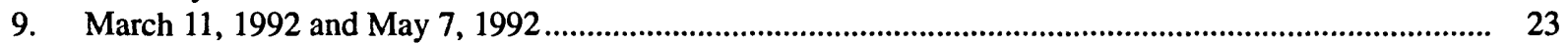

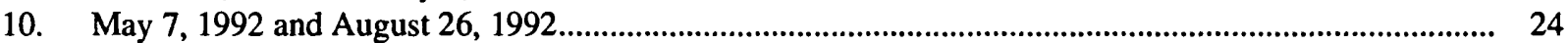

11-15. Graphs showing preliminary computed volumetric water content for UE-29 UZN \#92 for:

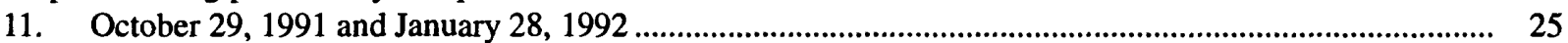

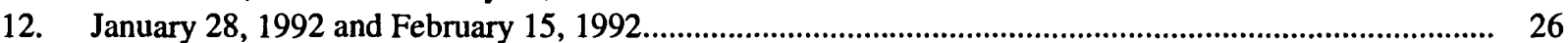

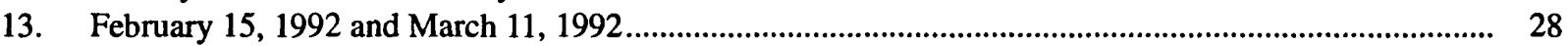

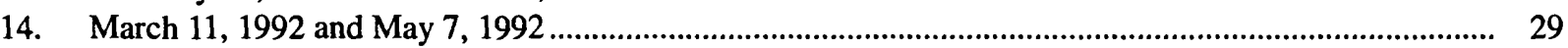

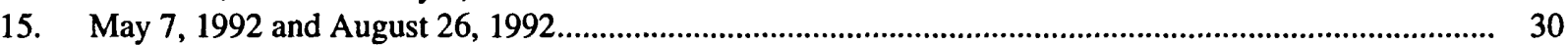

16-18. Hydrographs showing depth-to-water measurements in:

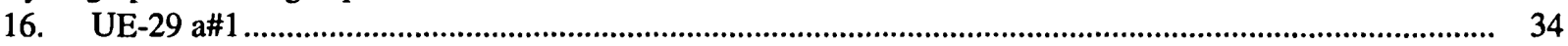

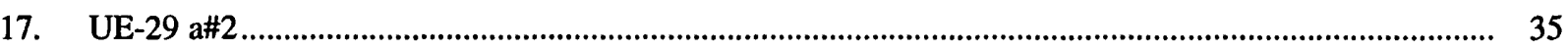

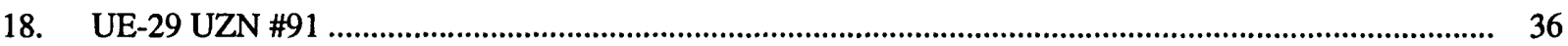

\section{TABLES}

1. Precipitation totals for the UE-29 UZN \#91 and UE-29 UZN \#92 sites .............................................................

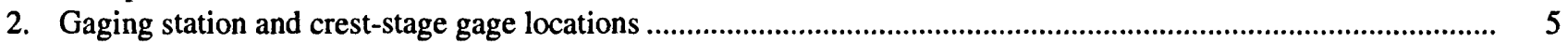

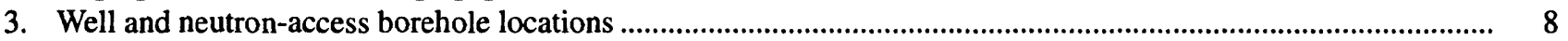

4. Preliminary computed volumetric water content from neutron logging in UE-29 UZN \#91 ................................. 9

5. Preliminary computed volumetric water content from neutron logging in UE-29 UZN \#92 ................................ 14

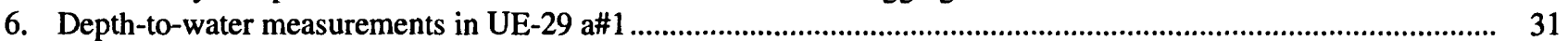

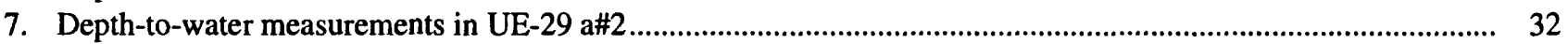

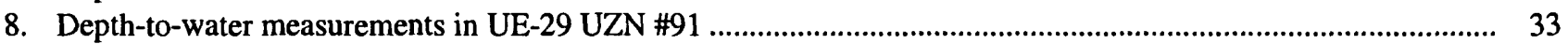




\section{CONVERSION FACTORS AND VERTICAL DATUM}

\begin{tabular}{rll}
\hline Multiply & By & To obtain \\
\hline & & \\
kilometer $(\mathrm{km})$ & 0.6214 & mile (mi) \\
meter $(\mathrm{m})$ & 3.281 & foot $(\mathrm{ft})$ \\
millimeter $(\mathrm{mm})$ & 0.03937 & inch (in.) \\
centimeter $(\mathrm{cm})$ & 0.3937 & inch (in.) \\
\hline
\end{tabular}

Degree Celsius $\left({ }^{\circ} \mathrm{C}\right)$ may be converted to degree Fahrenheit $\left({ }^{\circ} \mathrm{F}\right)$ by using the following equation:

$$
{ }^{\circ} \mathrm{F}=9 / 5\left({ }^{\circ} \mathrm{C}\right)+32 \text {. }
$$

Sea level: In this report "sea level" refers to the National Geodetic Vertical Datum of 1929 (NGVD of 1929)-a geodetic datum derived from a general adjustment of the first-order level nets of both the United States and Canada, formerly called Sea Level Datum of 1929. 


\title{
Selected Hydrologic Data from Fortymile Wash in the Yucca Mountain Area, Nevada, Water Year 1992
}

\author{
By Charles S. Savard
}

\section{Abstract}

Precipitation totals of 245 and $210 \mathrm{~mm}$ were measured at UE-29 UZN \#91 and UE-29 UZN \#92 respectively, during the 1992 water year, October 1, 1991 to September 30, 1992. Approximately ninety percent of the precipitation fell during the period December 27 to April 2. Localized streamflow was generated in the Fortymile Wash drainage basin during the February 12-15, 1992 and March 31, 1992 precipitation, and infiltrated into the streambed materials. The streamflow went across the UE-29 UZN \#91 neutron-access borehole location and within several meters of the UE-29 UZN \#92 location. Neutron logging in these boreholes showed increases in the volumetric water content of the unsaturated alluvium and indicated streamflow infiltrated to a depth of approximately 5 meters. The volumetric water content in the upper 5 meters then gradually decreased during the remaining part of the water year. Ground-water levels rose over one meter in wells UE-29 a\#1 and UE-29 a\#2, and one-half meter in neutron-access borehole UE-29 UZN \#91 following the streamflows. Water level declines of 0.5 meter in UE-29 a\#1 and rises of 0.2 meter in UE-29 a\#2 and 0.1 meter in UE-29 UZN \#91 coincided with a June 29, 1992 earthquake at the Little Skull Mountain, located approximately 27 kilometers southeast of the wells.

\section{INTRODUCTION}

The Yucca Mountain area currently is being evaluated by the U.S. Department of Energy for its suitability to store high-level nuclear waste in a mined, underground repository (U.S. Department of Energy, 1988). Hydrologic data are being collected by the U.S. Geological Survey throughout a 150-square kilometer study area about $150 \mathrm{~km}$ northwest of Las Vegas in southern Nevada (fig. 1) for site characterization studies. Ongoing hydrologic studies are investigating atmospheric precipitation, streamflow, movement of water through the unsaturated zone, movement of water through the saturated zone, and paleohydrology.

The Fortymile Wash recharge study involves some components of each of these studies. Fortymile Wash is an ephemeral stream near Yucca Mountain with tributaries draining the east side of Yucca Mountain and then forming a distributary system in the Amargosa Desert. Data collected during the study will be used to determine the amount of ground-water recharge from Fortymile Wash to the ground-water flow system which has been proposed by Czarnecki and Waddell (1984), Claassen (1985), White and Chuma (1987), and Benson and Klieforth (1989). Understanding the ground-water flow system is important because it is a possible mechanism for radionuclide migration from the potential repository to the accessible environment, and is necessary for an evaluation of the environmental issues involved with siting the potential repository.

\section{Purpose and Scope}

The purpose of this report is to present selected hydrologic data for the 1992 Water Year (WY), which is October 1, 1991 to September 30, 1992. Precipitation totals and preliminary neutron logging results from two sites (UE-29 UZN \#91 and UE-29 UZN \#92), miscellaneous streamflow observations, and depth-toground-water data from three sites (UE-29 a\#1, UE-29 a\#2, and UE-29 UZN \#91) are presented in this report. These data are considered important to understanding recharge processes to the ground-water system in Fortymile Wash. The neutron logging results are considered preliminary since a final calibration equation to convert neutron counts to volumetric water content has not been developed. However, a preliminary equation used to compute volumetric water content was considered adequate to show qualitative differences in the neutron-logging profiles. 


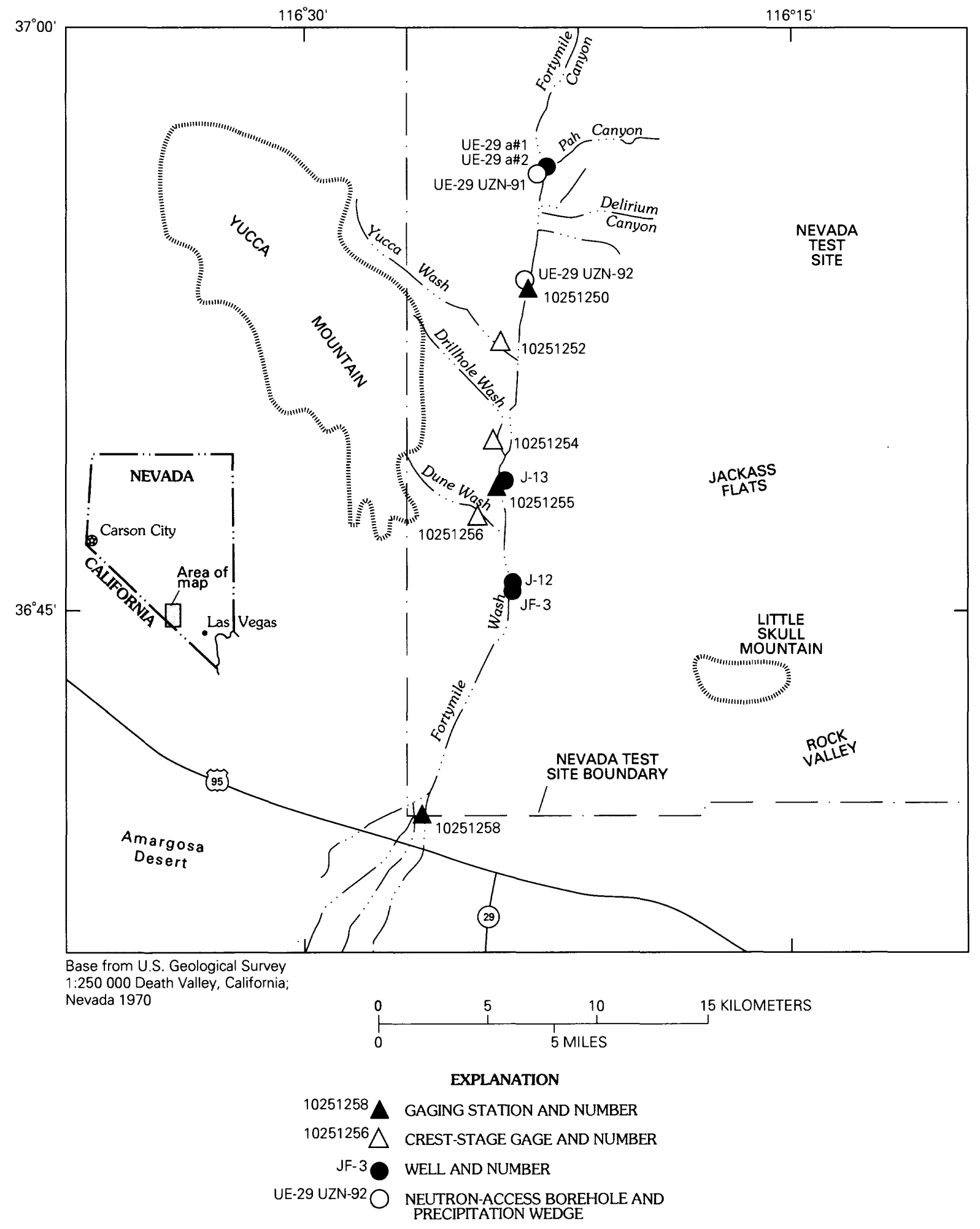

Figure 1. Location of gaging stations, crest-stage gages, neutron-access boreholes, and wells. 


\section{Previous Work}

The U.S. Geological Survey has been investigating the hydrology of the Yucca Mountain area since the 1960's as part of other Nevada Test Site studies (Moore, 1961 \& 1962; Thordarson and others, 1967; Young, 1972; and Winograd and Thordarson, 1975). Waddell $(1982,1984)$, Robison (1984), Waddell and others (1984), Robison and others (1988), Gemmel (1990), O'Brien (1991), and Luckey and others (1993) presented ground-water level data for wells in the Fortymile Wash and Yucca Mountain area. Squires and Young (1984) and Pabst and others (1993) investigated streamflow in Fortymile Wash. Huber (1988) investigated the geomorphic evolution of Fortymile Wash.

\section{Acknowledgments}

Numerous personnel helped in the collection, compilation, and quality assurance of the data included in this report. Those making notable specific contributions were: Dale Ambos for compiling the precipitation data; Lorraine Flint, Joe Gonzales, and David Hudson for compiling the neutron logging data; and Alan Flint for providing the preliminary neutronlogging calibration equation.

\section{PRECIPITATION DATA}

Nonrecording precipitation wedges were mounted on posts near the neutron-access borehole locations, UE-29 UZN \#91 and UE-29 UZN \#92 (fig. 1), during the 1992 WY. Differences between successive readings were used to determine the total amount of precipitation that fell in the intervening period (table 1). Oil was added to the wedges to prevent evaporation of the precipitation between readings. During the winter, antifreeze was added so snowfall would melt, and to keep the precipitation from freezing.

The total precipitation measured for the 1992 WY was $245 \mathrm{~mm}$ at UE-29 UZN \#91 and $210 \mathrm{~mm}$ at UE-29 UZN \#92. December 27, 1991 to April 2, 1992 was the wettest period of the water year when a series of storms in the Fortymile Wash drainage basin accounted for 89 percent of the total annual precipitation measured at the UE-29 UZN \#91 site and 94 percent measured at the UE-29 UZN \#92 site (fig. 2).

\section{STREAMFLOW DATA}

Streamflow data were collected from a network of three continuous recording gaging stations and three crest-stage gages in the lower Fortymile Wash drainage basin. Locations of the gages are shown in fig. 1 and described in table 2. Miscellaneous streamflow observations, such as velocity estimates and high-water marks, and the distances the streamflow traveled were made during and after the periods of streamflow, February 12-15 and March 31, 1992. Peak flow and mean daily discharge data at the gaging stations and crest-stage gages are contained in a separate report series (Pabst and others, 1993 and Kane and others, in press). This section of the report documents miscellaneous streamflow observations and evidence from field reconnaissance for the distances the streamflow traveled.

Yucca Wash had streamflow events on February 12 and 14 . The February 12 event was observed near peak flow. A subsequent visit to the wash found evidence of the February 14 streamflow event. The February 14 event had a lower peak discharge than the February 12 event based on deposits and wash lines left by the two streamflow events. Recently deposited gravel and seed lines along the channel indicated streamflow reached the main Fortymile Wash channels approximately $450 \mathrm{~m}$ below the crest-stage gage. The streamflow traveled approximately 30 to $40 \mathrm{~m}$ down the main Fortymile Wash channel before completely infiltrating into the streambed sediments.

Delirium Canyon tributary and the two unnamed tributaries just to the north and the south had streamflow events on February 12. Recent sand and gravel deposits indicated streamflow in the three tributaries reached the main Fortymile Wash channel. No evidence of streamflow in Fortymile Wash was observed upstream of the confluence of Fortymile Wash and the northernmost tributary. Recent deposits of sand and gravel, seed lines, and wash lines indicated the Fortymile Wash streamflow event traveled past the Fortymile Wash at Narrows gaging station and continued to flow downstream for a distance of approximately $2.5 \mathrm{~km}$. All of the measured streamflow at the Fortymile Wash at the Narrows gage infiltrated into the streambed materials. The lateral extent of the streamflow in Fortymile Wash was approximately 3 to $5 \mathrm{~m}$ away from the neutron-access borehole UE-29 UZN \#92 just upstream of the Narrows gage.

Streamflow velocity was estimated at 2 to 3 meters per second for a reach in the Delirium Canyon tributary approximately 20 meters above the road crossing at 1520 hours on February 12. During a subsequent visit on February 13, the channel reach where 
Table 1. Precipitation totals for the UE-29 UZN \#91 and UE-29 UZN \#92 sites

[NR, gage not read]

\begin{tabular}{llcccc}
\hline \multicolumn{2}{c}{ Period } & \multicolumn{2}{c}{$\begin{array}{c}\text { UE-29 UZN *91 } \\
\text { precipitation } \\
\text { gage totals }\end{array}$} & \multicolumn{2}{c}{$\begin{array}{c}\text { UE-29 UZN *92 } \\
\text { precipitation } \\
\text { gage totals }\end{array}$} \\
\hline Begin date & \multicolumn{1}{c}{ End date } & (inches) & (mm) & (inches) & (mm) \\
\hline Oct. 1, 1991 & Oct. 28, 1991 & 0.25 & 6 & 0.09 & 2 \\
Oct. 28, 1991 & Nov. 15, 1991 & 0.01 & 0 & 0.00 & 0 \\
Nov. 15, 1991 & Dec. 10, 1991 & 0.13 & 3 & 0.10 & 3 \\
Dec. 10, 1991 & Dec. 27, 1991 & 0.08 & 2 & NR & NR \\
Dec. 27, 1991 & Jan. 7, 1992 & 1.73 & 44 & $1.81^{*}$ & $46^{*}$ \\
& & & & & \\
Jan. 7, 1992 & Feb. 10, 1992 & 0.80 & 20 & 0.95 & 24 \\
Feb. 10, 1992 & Feb. 14, 1992 & NR & NR & 1.70 & 43 \\
Feb. 14, 1992 & Feb. 19, 1992 & $2.65 * *$ & $67 * *$ & 0.40 & 10 \\
Feb. 19, 1992 & Mar. 4, 1992 & 0.64 & 16 & 0.73 & 19 \\
Mar. 4, 1992 & Mar. 9, 1992 & 0.18 & 5 & 0.17 & 4 \\
& & & & & \\
Mar. 9, 1992 & Mar. 23, 1992 & 1.08 & 27 & 0.95 & 24 \\
Mar. 23, 1992 & Mar. 30, 1992 & 0.70 & 18 & 0.50 & 13 \\
Mar. 30, 1992 & Apr. 2, 1992 & 0.79 & 20 & 0.55 & 14 \\
Apr. 2, 1992 & May 13, 1992 & 0.12 & 3 & 0.02 & 1 \\
May 13, 1992 & Jul. 8, 1992 & 0.02 & 1 & 0.02 & 1 \\
& & & & & \\
Jul. 8, 1992 & Jul. 16, 1992 & 0.17 & 4 & 0.04 & 1 \\
Aug. 16, 1992 & Aug. 3, 1992 & 0.29 & 7 & 0.05 & 1 \\
Aug. 3, 1992 & Aug. 17, 1992 & 0.00 & 0 & 0.20 & 5 \\
Aug. 17, 1992 & Sep. 30, 1992 & 0.00 & 0 & 0.00 & 0 \\
\hline & & & & & \\
& 1992 WY Total & 9.64 & 243 & 8.28 & 211 \\
\hline
\end{tabular}

*For the period Dec. 10, 1991 - Jan. 7, 1992.

**For the period Feb. 10, 1992 - Feb. 19, 1992.

velocity estimates were made was found to be filled with gravel deposited from the streamflow event. Comparison of photographs taken at the reach during (fig. 3) and after (fig. 4) the streamflow event, indicate the top of the gravel fill on February 13 was higher than the water surface was on February 12 during the streamflow event.

On February 13, Delirium Canyon tributary discharge was estimated at approximately 0.03 cubic meters per second in the channel 100 to $125 \mathrm{~m}$ upstream of the road crossing. The streamflow completely infiltrated into the streambed sediments rapidly and did not travel as far as the road crossing. It is unknown if this streamflow was part of the February 12 event and still in recession or a separate event.
Recent sand and gravel deposits and wash lines indicated Pah Canyon tributary to Fortymile Wash had a streamflow event during the period February 12 to 18 . The streamflow went into Fortymile Wash and downstream past the UE-29 UZN \#91 location. The neutronaccess borehole was located within the wetted channel. Sand and gravel deposits became smaller in lateral extent going downstream from Pah Canyon tributary, through the confluence of Pah Canyon tributary and Fortymile Wash, and past the neutron-access borehole location. This indicated the active channel was decreasing and streamflow was infiltrating into the streambed sediments. Some water came down Fortymile Wash from above Pah Canyon, but the majority of the water came down Pah Canyon tributary. 


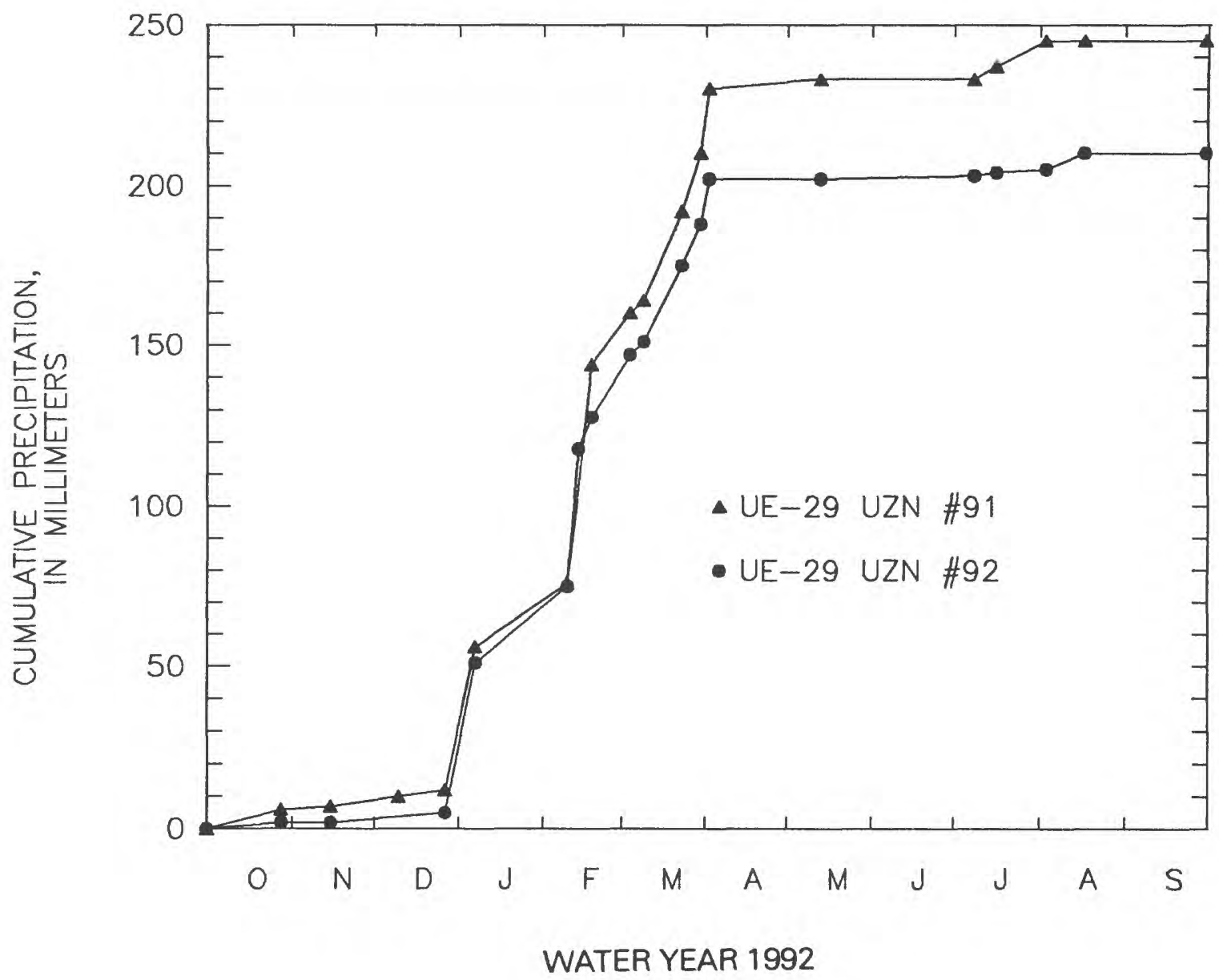

Figure 2. Cumulative precipitation at UE-29 UZN \#91 and UE-29 UZN \#92.

Table 2. Gaging station and crest-stage gage locations

[G, continuous recording gaging station; $C$, crest-stage gage]

\begin{tabular}{|c|c|c|c|c|c|}
\hline \multirow{2}{*}{$\begin{array}{l}\text { Station } \\
\text { number }\end{array}$} & \multirow{2}{*}{ Station name } & \multicolumn{2}{|c|}{ Location } & \multirow{2}{*}{$\begin{array}{l}\text { Gage } \\
\text { type }\end{array}$} & \multirow{2}{*}{$\begin{array}{c}\text { Drainage } \\
\text { area } \\
\left(\mathbf{m i}^{2}\right)\end{array}$} \\
\hline & & Latitude & Longitude & & \\
\hline 10251250 & Fortymile Wash at Narrows, Nevada Test Site, Nevada & $36^{\circ} 53^{\prime} 13^{\prime \prime}$ & $116^{\circ} 22^{\prime} 50^{\prime \prime}$ & G & 258 \\
\hline 10251252 & Yucca Wash near mouth, Nevada Test Site, Nevada & $36^{\circ} 51^{\prime} 58^{\prime \prime}$ & $116^{\circ} 23^{\prime} 38^{\prime \prime}$ & C & 17.0 \\
\hline 10251254 & Drillhole Wash at mouth, Nevada Test Site, Nevada & $36^{\circ} 49^{\prime} 13^{\prime \prime}$ & $116^{\circ} 23^{\prime} 52^{\prime \prime}$ & C & 16.3 \\
\hline 10251255 & Fortymile Wash near Well J-13, Nevada Test Site, Nevada & $36^{\circ} 48^{\prime} 27^{\prime \prime}$ & $116^{\circ} 24^{\prime} 01^{\prime \prime}$ & G & 304 \\
\hline 10251256 & Dune Wash near Busted Butte, Nevada Test Site, Nevada & $36^{\circ} 47^{\prime} 35^{\prime \prime}$ & $116^{\circ} 24^{\prime} 29^{\prime \prime}$ & C & 6.77 \\
\hline 10251258 & Fortymile Wash near Amargosa Valley, Nevada Test Site, Nevada & $36^{\circ} 40^{\prime} 18^{\prime \prime}$ & $116^{\circ} 26^{\prime} 03^{\prime \prime}$ & G & 316 \\
\hline
\end{tabular}




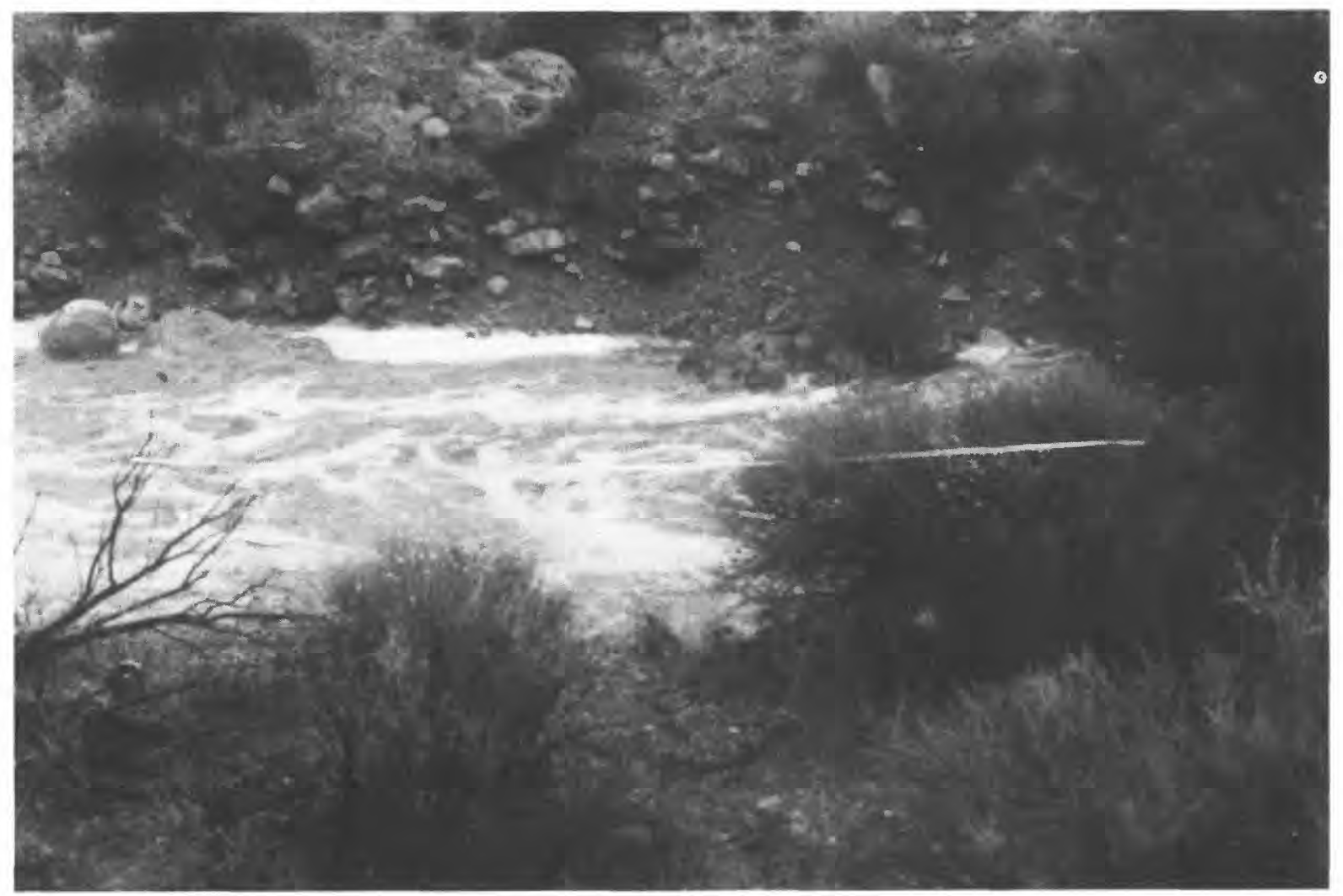

Figure 3. Delirium Canyon tributary velocity section on February 12, 1992.

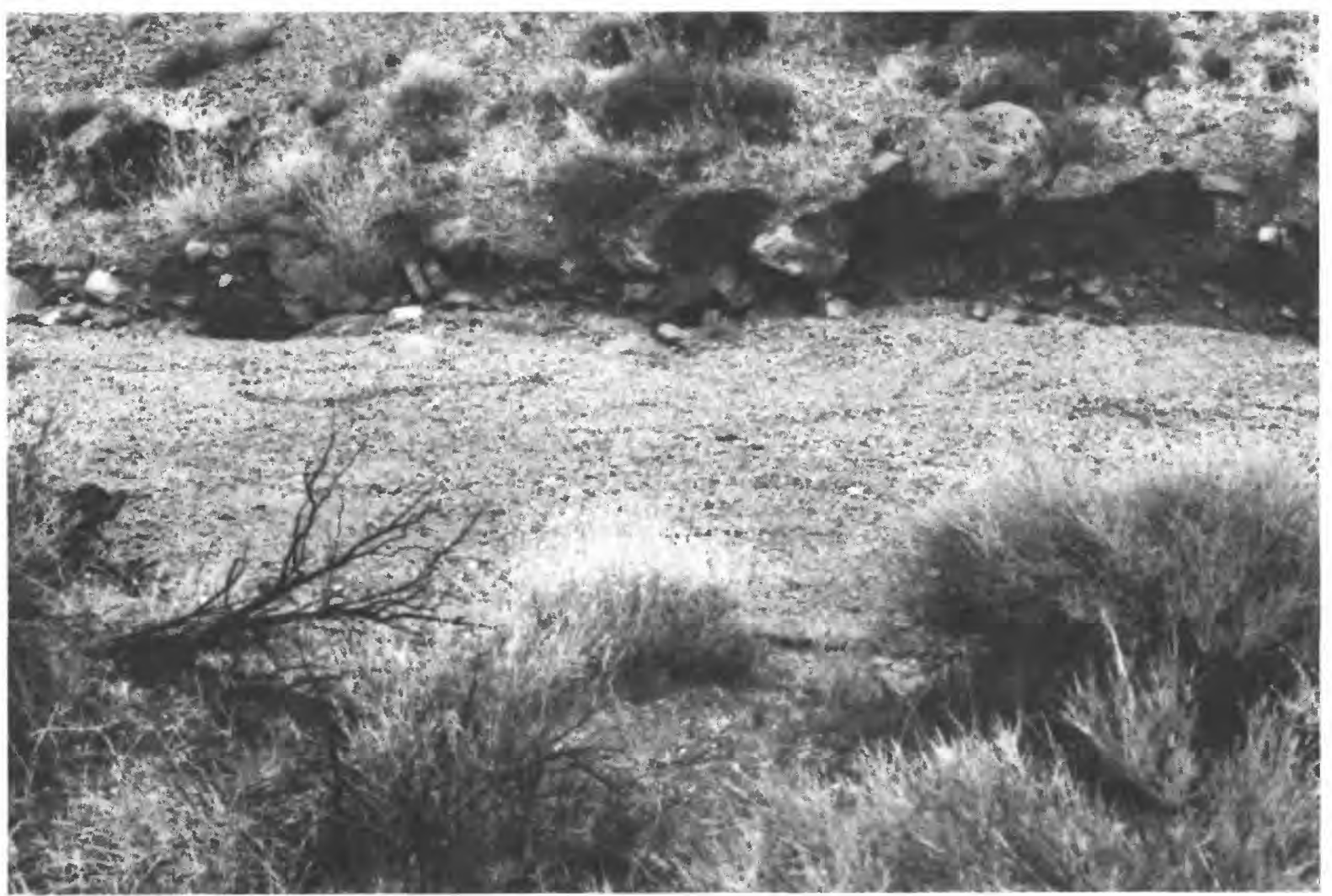

Figure 4. Delirum Canyon tributary velocity section on February 13, 1992. 
The gravel deposits made it impossible to determine the wetted cross-sectional areas during the streamflow.

On March 31, evidence of a second streamflow event was found in Delirium Canyon and Pah Canyon tributaries to Fortymile Wash. At Delirium Canyon, a temporary road repair had been partially washed away and comparison between photographs taken on February 13 (fig. 4) and March 31 (fig. 5) showed deposition of gravel in the channel indicating a streamflow event had occurred. At UE-29 UZN \#91, reworking of sediment deposits and the breaching of a small, kicked-up flow dam indicated another streamflow event had traveled down Pah Canyon tributary and into Fortymile Wash. No other evidence from streamflow events were found in the lower Fortymile Wash drainage basin on March 31.

No streamflow was recorded at the two most southern gaging stations, Fortymile Wash near Well J-13 and Fortymile Wash near Amargosa Valley, during the 1992 WY. Also, no streamflow was recorded at the crest-stage gages, Drillhole Wash at mouth, and Dune Wash near Busted Butte.

Drainage areas for the gaging stations and creststage gages are listed in table 2. Field observations during and after the 1992 WY streamflow events indicate that not all of the drainage basin upstream of a gage contributes streamflow. For example, the streamflow measured at Fortymile Wash at Narrows gage on February 12 was the result of streamflow produced only in the Delirium Canyon area, a small portion of the 668 square $\mathrm{km}$ drainage basin. As a result, relations between streamflow and total upstream drainage area are difficult to establish. Establishing the contributing area during precipitation-streamflow events, rather than just the drainage area, will be important for future Fortymile Wash studies.

\section{UNSATURATED ZONE WATER-CONTENT PROFILES}

The water content of the unsaturated zone was monitored by neutron logging at UE-29 UZN \#91 and UE-29 UZN \#92. Both boreholes are located in the main Fortymile Wash channel. UE-29 UZN \#91 was drilled to a depth of $28.6 \mathrm{~m}$, and UE-29 UZN \#92 to $36.6 \mathrm{~m}$ (table 3 ). Only the water content of the alluvium and colluvium was monitored in UE-29 UZN \#91 because the contact with the underlying volcanic bedrock is $20.2 \mathrm{~m}$ below the measurement point (M.P. Chornack, U.S. Geological Survey, oral com-

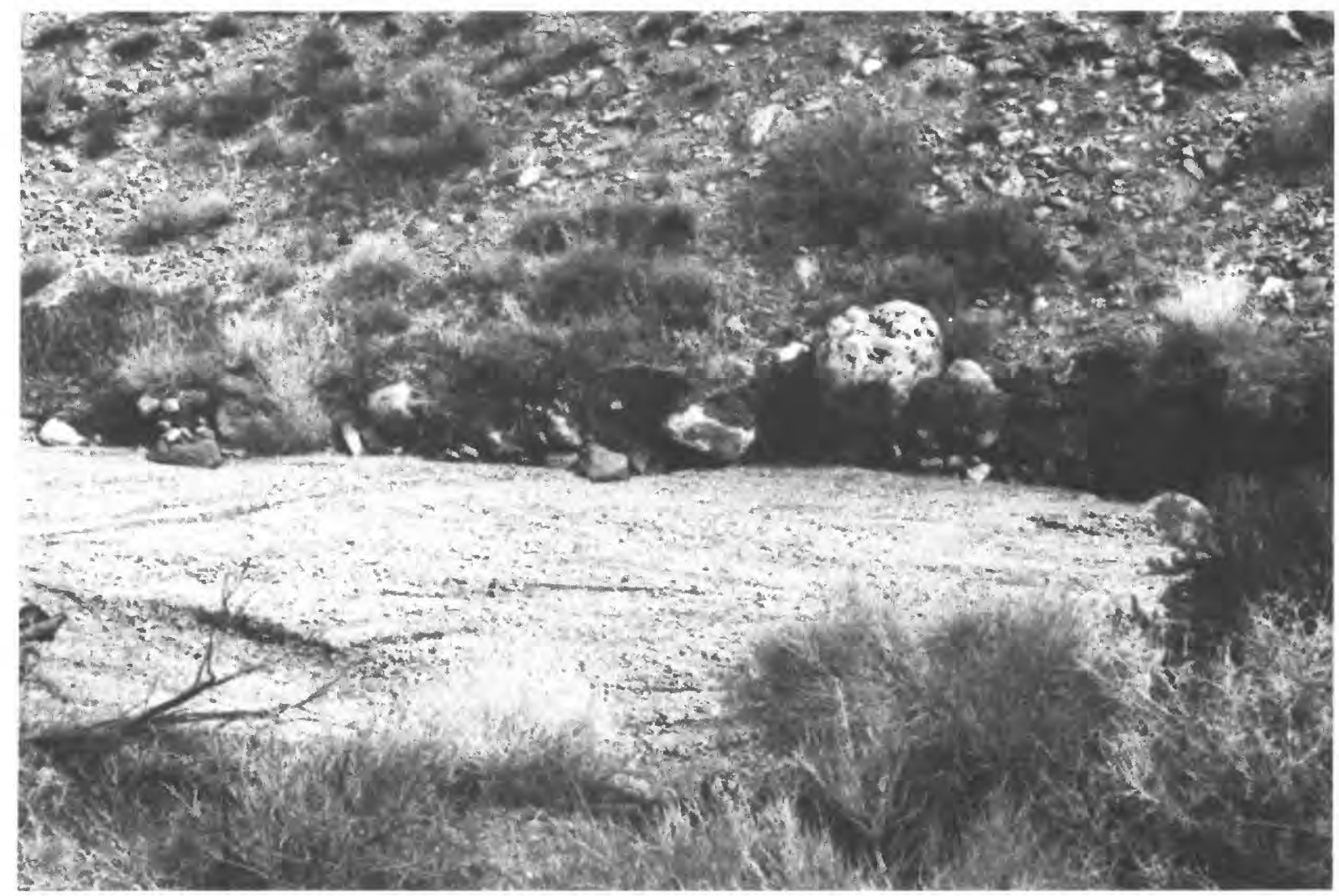

Figure 5. Delirium Canyon tributary velocity section on March 31, 1992. 
Table 3. Well and neutron-access borehole locations

\begin{tabular}{|c|c|c|c|c|c|}
\hline \multirow[t]{2}{*}{ Name } & \multirow[t]{2}{*}{ Site ID } & \multicolumn{2}{|c|}{ Location } & \multicolumn{2}{|c|}{$\begin{array}{c}\text { Depth of open } \\
\text { intervai beiow land } \\
\text { surface }\end{array}$} \\
\hline & & Latitude & Longitude & $\begin{array}{c}\text { Top } \\
\text { (meters) }\end{array}$ & $\begin{array}{c}\text { Bottom } \\
\text { (meters) }\end{array}$ \\
\hline UE-29 a\#1 & 365629116222601 & $36^{\circ} 56^{\prime} 29^{\prime \prime}$ & $116^{\circ} 22^{\prime} 26^{\prime \prime}$ & 10.7 & 65.5 \\
\hline \multirow[t]{2}{*}{ UE-29 a\#2 } & 365629116222602 & $36^{\circ} 56^{\prime 2} 29^{\prime \prime}$ & $116^{\circ} 22^{\prime} 26^{\prime \prime}$ & 86.9 & 213 \\
\hline & & & & 247 & 421 \\
\hline UE-29 UZN \#91 & 365624116222901 & $36^{\circ} 56^{\prime} 24^{\prime \prime}$ & $116^{\circ} 22^{\prime} 29^{\prime \prime}$ & 27.1 & 28.6 \\
\hline UE-29 UZN \#92 & 365324226225101 & $36^{\circ} 53^{\prime} 14^{\prime \prime}$ & $116^{\circ} 22^{\prime} 51^{\prime \prime}$ & 32.0 & 36.6 \\
\hline \multirow[t]{2}{*}{$\mathrm{J}-13$} & 364829116234001 & $36^{\circ} 48^{\prime} 28^{\prime \prime}$ & $116^{\circ} 23^{\prime} 40^{\prime \prime}$ & 304 & 424 \\
\hline & & & & 820 & 1,010 \\
\hline $\mathrm{J}-12$ & 364554116232401 & $36^{\circ} 45^{\prime} 54^{\prime \prime}$ & $116^{\circ} 23^{\prime} 24^{\prime \prime}$ & 265 & 347 \\
\hline JF-3 & 364528116232201 & $36^{\circ} 45^{\prime} 28^{\prime \prime}$ & $116^{\circ} 23^{\prime 2} 22^{\prime \prime}$ & 224 & 347 \\
\hline
\end{tabular}

mun., 1993) and below the water table. The alluvium and colluvium contact with the underlying volcanic bedrock is $18.3 \mathrm{~m}$ below the measurement point in UE-29 UZN \#92, so the vertical water-content profiles represent conditions in the alluvium, colluvium, and the volcanic bedrock to a depth of $19.4 \mathrm{~m}$.

The hand-held neutron logging meter outputs the number of counts, which are proportional to the water content of the surrounding geologic medium (Gardner, 1986). The neutron logging meter has a resolution range less than one meter, thus the moisture contents derived from the neutron logging only represent a small portion of the Fortymile Wash drainage basin.

Repeated measurements over the same intervals and depths allows for qualitative comparison of changes in moisture content. A preliminary calibration equation for the neutron meter provides a quantitative measure of the differences between measurements. The preliminary equation (A.L. Flint, U.S. Geological Survey, oral commun., 1993) used to convert the neutron counts to volumetric water content is,

$$
\text { VWC }=\left(4.8639 \times 10^{-9} \times C^{2}\right)+\left(1.3463 \times 10^{-5} \times C\right)-0.01386
$$

where,

VWC is volumetric water content in $\mathrm{cm}^{3} / \mathrm{cm}^{3}$, and

C is the neutron count output from the meter after the 16 second counting interval.

The neutron logging meter was hand lowered down the neutron-access borehole with a depth-marked cable allowing vertical profiles of the water content to be made throughout the year (tables 4 and 5). Neutron counts were recorded every tenth of a meter from the land surface to five meters below the measurement point, after which counts were taken every three tenths of a meter. Both measurement points for the neutronaccess boreholes are seven tenths of a meter above the land surface. Readings at UE-29 UZN \#91 were stopped at $16.1 \mathrm{~m}$ to prevent the neutron tool from becoming immersed in the ground water and damaging the tool. Readings at UE-29 UZN \#92 were stopped at $19.4 \mathrm{~m}$ depth. Both neutron holes were logged on the same day except for February 15, 1992, when road conditions from the recent streamflow made the road to UE-29 UZN \#91 impassable. Readings at $16.1 \mathrm{~m}$ on May 7, 1992 for UE-29 UZN \#91 and $17.6 \mathrm{~m}$ on October 29, 1992 for UE-29 UZN \#92 were not recorded due to operator error.

At UE-29 UZN \#91, there were no major differences from October 29 to January 28 in the vertical volumetric water-content profiles except for a slight increase from 0.7 to $1.0 \mathrm{~m}$ depth (fig. 6). After the February 12 streamflow event, the February 21 profile increased in water content from 0.7 to $5.0 \mathrm{~m}$ (fig. 7). From February 21 to March 11, the profile decreased in water content from 0.7 to $4.8 \mathrm{~m}$ and increased from 4.9 to $5.3 \mathrm{~m}$ (fig. 8). From March 11 to May 7, the profile decreased in water content from 0.7 to $4.8 \mathrm{~m}$ and increased from 4.9 to $5.6 \mathrm{~m}$ (fig. 9). From May 7 to August 26, the profile decreased in water content from 0.7 to $5.6 \mathrm{~m}$ (fig. 10). All profiles throughout the 1992 WY did not show any appreciable differences below $5.9 \mathrm{~m}$.

At UE-29 UZN \#92, there were no major differences from October 29 to January 28 in the vertical volumetric water-content profiles except for a slight increase from 0.7 to $1.2 \mathrm{~m}$ depth (fig. 11). After the February 12 streamflow event, the February 15 profile increased from 0.7 to $5.3 \mathrm{~m}$ (fig. 12). From February 
Table 4. Preliminary computed volumetric water content from neutron logging in UE-29 UZN \#91

[m, meter; $\mathrm{cm}^{3}$, cubic centimeters; measurement point is top of casing after cap is removed]

\begin{tabular}{|c|c|c|c|c|c|c|c|}
\hline \multirow{2}{*}{$\begin{array}{l}\text { Depth below } \\
\text { measurement } \\
\text { point } \\
\text { (m) }\end{array}$} & \multicolumn{7}{|c|}{$\begin{array}{l}\text { Computed volumetric water content } \\
\qquad\left(\mathrm{cm}^{3} / \mathrm{cm}^{3}\right)\end{array}$} \\
\hline & Oct. 29, 1991 & Dec. 3, 1991 & Jan. 28, 1992 & Feb. 21, 1992 & Feb. 25, 1992 & Mar. 6, 1992 & Mar. 11, 1992 \\
\hline 0.7 & 0.140 & 0.153 & 0.190 & 0.220 & 0.221 & 0.218 & 0.220 \\
\hline 0.8 & 0.083 & 0.085 & 0.115 & 0.134 & 0.139 & 0.141 & 0.130 \\
\hline 0.9 & 0.066 & 0.067 & 0.092 & 0.125 & 0.124 & 0.132 & 0.128 \\
\hline 1.0 & 0.065 & 0.066 & 0.084 & 0.132 & 0.124 & 0.136 & 0.128 \\
\hline 1.1 & 0.062 & 0.066 & 0.074 & 0.123 & 0.124 & 0.129 & 0.130 \\
\hline 1.2 & 0.071 & 0.068 & 0.068 & 0.133 & 0.127 & 0.136 & 0.129 \\
\hline 1.3 & 0.073 & 0.079 & 0.079 & 0.147 & 0.141 & 0.144 & 0.135 \\
\hline 1.4 & 0.083 & 0.082 & 0.084 & 0.157 & 0.162 & 0.159 & 0.156 \\
\hline 1.5 & 0.088 & 0.084 & 0.091 & 0.180 & 0.159 & 0.162 & 0.158 \\
\hline 1.6 & 0.086 & 0.085 & 0.081 & 0.157 & 0.156 & 0.151 & 0.150 \\
\hline 1.7 & 0.085 & 0.081 & 0.083 & 0.144 & 0.140 & 0.136 & 0.132 \\
\hline 1.8 & 0.083 & 0.086 & 0.084 & 0.152 & 0.150 & 0.146 & 0.144 \\
\hline 1.9 & 0.091 & 0.091 & 0.088 & 0.153 & 0.153 & 0.144 & 0.149 \\
\hline 2.0 & 0.088 & 0.080 & 0.082 & 0.151 & 0.151 & 0.142 & 0.143 \\
\hline 2.1 & 0.082 & 0.085 & 0.079 & 0.155 & 0.148 & 0.153 & 0.151 \\
\hline 2.2 & 0.073 & 0.073 & 0.073 & 0.156 & 0.154 & 0.141 & 0.141 \\
\hline 2.3 & 0.074 & 0.071 & 0.075 & 0.144 & 0.140 & 0.142 & 0.145 \\
\hline 2.4 & 0.074 & 0.075 & 0.074 & 0.170 & 0.170 & 0.169 & 0.163 \\
\hline 2.5 & 0.067 & 0.068 & 0.074 & 0.181 & 0.181 & 0.165 & 0.164 \\
\hline 2.6 & 0.063 & 0.058 & 0.059 & 0.161 & 0.155 & 0.153 & 0.153 \\
\hline 2.7 & 0.051 & 0.056 & 0.053 & 0.125 & 0.122 & 0.116 & 0.112 \\
\hline 2.8 & 0.056 & 0.059 & 0.060 & 0.126 & 0.125 & 0.114 & 0.120 \\
\hline 2.9 & 0.066 & 0.064 & 0.066 & 0.142 & 0.139 & 0.134 & 0.128 \\
\hline 3.0 & 0.059 & 0.059 & 0.064 & 0.157 & 0.148 & 0.138 & 0.144 \\
\hline 3.1 & 0.055 & 0.051 & 0.055 & 0.153 & 0.135 & 0.134 & 0.136 \\
\hline 3.2 & 0.046 & 0.044 & 0.046 & 0.146 & 0.136 & 0.148 & 0.132 \\
\hline 3.3 & 0.040 & 0.043 & 0.041 & 0.165 & 0.158 & 0.149 & 0.146 \\
\hline 3.4 & 0.037 & 0.042 & 0.041 & 0.160 & 0.158 & 0.155 & 0.156 \\
\hline 3.5 & 0.035 & 0.033 & 0.037 & 0.151 & 0.156 & 0.145 & 0.148 \\
\hline 3.6 & 0.034 & 0.032 & 0.033 & 0.130 & 0.125 & 0.132 & 0.129 \\
\hline 3.7 & 0.036 & 0.035 & 0.037 & 0.124 & 0.118 & 0.115 & 0.116 \\
\hline 3.8 & 0.045 & 0.044 & 0.045 & 0.133 & 0.127 & 0.123 & 0.121 \\
\hline 39 & 0.053 & 0.057 & 0.060 & 0.161 & 0.155 & 0.140 & 0.143 \\
\hline 4.0 & 0.069 & 0.066 & 0.069 & 0.223 & 0.207 & 0.204 & 0.198 \\
\hline
\end{tabular}


Table 4. Preliminary computed volumetric water content from neutron logging in UE-29 UZN \#91 --Continued

\begin{tabular}{|c|c|c|c|c|c|c|c|}
\hline \multirow{2}{*}{$\begin{array}{l}\text { Depth below } \\
\text { measurement } \\
\text { point } \\
\text { (m) }\end{array}$} & \multicolumn{7}{|c|}{$\begin{array}{l}\text { Computed volumetric water content } \\
\qquad\left(\mathrm{cm}^{3} / \mathrm{cm}^{3}\right)\end{array}$} \\
\hline & Oct. 29, 1991 & Dec. 3, 1991 & Jan. 28, 1992 & Feb. 21, 1992 & Feb. 25, 1992 & Mar. 6, 1992 & Mar. 11, 1992 \\
\hline 4.1 & 0.075 & 0.071 & 0.071 & 0.216 & 0.209 & 0.203 & 0.203 \\
\hline 4.2 & 0.075 & 0.076 & 0.076 & 0.183 & 0.172 & 0.165 & 0.163 \\
\hline 4.3 & 0.074 & 0.077 & 0.075 & 0.158 & 0.151 & 0.148 & 0.144 \\
\hline 4.4 & 0.070 & 0.073 & 0.073 & 0.153 & 0.146 & 0.137 & 0.137 \\
\hline 4.5 & 0.081 & 0.083 & 0.083 & 0.170 & 0.169 & 0.160 & 0.156 \\
\hline 4.6 & 0.088 & 0.087 & 0.085 & 0.161 & 0.154 & 0.155 & 0.143 \\
\hline 4.7 & 0.084 & 0.089 & 0.088 & 0.156 & 0.150 & 0.149 & 0.151 \\
\hline 4.8 & 0.088 & 0.085 & 0.092 & 0.158 & 0.151 & 0.151 & 0.148 \\
\hline 4.9 & 0.087 & 0.087 & 0.092 & 0.152 & 0.156 & 0.144 & 0.151 \\
\hline 5.0 & 0.087 & 0.092 & 0.087 & 0.134 & 0.148 & 0.146 & 0.144 \\
\hline 5.3 & 0.093 & 0.088 & 0.092 & 0.091 & 0.101 & 0.115 & 0.126 \\
\hline 5.6 & 0.085 & 0.092 & 0.093 & 0.095 & 0.088 & 0.096 & 0.094 \\
\hline 5.9 & 0.089 & 0.088 & 0.097 & 0.090 & 0.090 & 0.088 & 0.089 \\
\hline 6.2 & 0.085 & 0.083 & 0.082 & 0.077 & 0.087 & 0.082 & 0.086 \\
\hline 6.5 & 0.080 & 0.074 & 0.075 & 0.075 & 0.073 & 0.074 & 0.074 \\
\hline 6.8 & 0.071 & 0.065 & 0.075 & 0.073 & 0.072 & 0.072 & 0.071 \\
\hline 7.1 & 0.067 & 0.068 & 0.068 & 0.075 & 0.070 & 0.070 & 0.063 \\
\hline 7.4 & 0.070 & 0.070 & 0.066 & 0.073 & 0.070 & 0.067 & 0.069 \\
\hline 7.7 & 0.066 & 0.068 & 0.066 & 0.067 & 0.066 & 0.065 & 0.065 \\
\hline 8.0 & 0.076 & 0.071 & 0.076 & 0.078 & 0.075 & 0.075 & 0.075 \\
\hline 8.3 & 0.077 & 0.071 & 0.073 & 0.070 & 0.071 & 0.069 & 0.068 \\
\hline 8.6 & 0.067 & 0.066 & 0.067 & 0.074 & 0.066 & 0.071 & 0.069 \\
\hline 8.9 & 0.089 & 0.081 & 0.089 & 0.091 & 0.092 & 0.089 & 0.087 \\
\hline 9.2 & 0.082 & 0.083 & 0.089 & 0.084 & 0.085 & 0.085 & 0.084 \\
\hline 9.5 & 0.087 & 0.084 & 0.081 & 0.081 & 0.084 & 0.083 & 0.086 \\
\hline 9.8 & 0.108 & 0.107 & 0.114 & 0.114 & 0.113 & 0.122 & 0.117 \\
\hline 10.1 & 0.084 & 0.087 & 0.090 & 0.088 & 0.089 & 0.085 & 0.088 \\
\hline 10.4 & 0.098 & 0.106 & 0.105 & 0.104 & 0.098 & 0.097 & 0.099 \\
\hline 10.7 & 0.114 & 0.110 & 0.110 & 0.119 & 0.117 & 0.121 & 0.111 \\
\hline 11.0 & 0.089 & 0.101 & 0.100 & 0.103 & 0.104 & 0.105 & 0.104 \\
\hline 11.3 & 0.095 & 0.089 & 0.097 & 0.098 & 0.096 & 0.099 & 0.098 \\
\hline 11.6 & 0.103 & 0.103 & 0.095 & 0.102 & 0.099 & 0.102 & 0.103 \\
\hline 11.9 & 0.150 & 0.158 & 0.148 & 0.155 & 0.155 & 0.156 & 0.156 \\
\hline 12.2 & 0.128 & 0.127 & 0.130 & 0.127 & 0.131 & 0.131 & 0.132 \\
\hline 12.5 & 0.169 & 0.168 & 0.167 & 0.170 & 0.160 & 0.171 & 0.169 \\
\hline
\end{tabular}


Table 4. Preliminary computed volumetric water content from neutron logging in UE-29 UZN \#91 --Continued

\begin{tabular}{|c|c|c|c|c|c|c|c|}
\hline \multirow{2}{*}{$\begin{array}{l}\text { Depth below } \\
\text { measurement } \\
\text { point } \\
\text { (m) }\end{array}$} & \multicolumn{7}{|c|}{$\begin{array}{l}\text { Computed volumetrlc water content } \\
\qquad\left(\mathrm{cm}^{3} / \mathrm{cm}^{3}\right)\end{array}$} \\
\hline & Oct. 29, 1991 & Dec. 3, 1991 & Jan. 28, 1992 & Feb. 21, 1992 & Feb. 25, 1992 & Mar. 6, 1992 & Mar. 11, 1992 \\
\hline 12.8 & 0.171 & 0.168 & 0.165 & 0.167 & 0.160 & 0.161 & 0.161 \\
\hline 13.1 & 0.149 & 0.146 & 0.145 & 0.150 & 0.148 & 0.142 & 0.143 \\
\hline 13.4 & 0.139 & 0.149 & 0.145 & 0.141 & 0.138 & 0.133 & 0.146 \\
\hline 13.7 & 0.146 & 0.149 & 0.147 & 0.147 & 0.150 & 0.139 & 0.143 \\
\hline 14.0 & 0.130 & 0.126 & 0.127 & 0.125 & 0.127 & 0.127 & 0.123 \\
\hline 14.3 & 0.103 & 0.103 & 0.101 & 0.102 & 0.103 & 0.097 & 0.099 \\
\hline 14.6 & 0.086 & 0.088 & 0.087 & 0.094 & 0.088 & 0.089 & 0.090 \\
\hline 14.9 & 0.159 & 0.159 & 0.153 & 0.160 & 0.156 & 0.152 & 0.155 \\
\hline 15.2 & 0.180 & 0.188 & 0.184 & 0.188 & 0.187 & 0.184 & 0.181 \\
\hline 15.5 & 0.176 & 0.184 & 0.183 & 0.174 & 0.177 & 0.181 & 0.184 \\
\hline 15.8 & 0.168 & 0.166 & 0.163 & 0.164 & 0.166 & 0.174 & 0.173 \\
\hline 16.1 & 0.171 & 0.168 & 0.166 & 0.170 & 0.178 & 0.160 & 0.173 \\
\hline
\end{tabular}

\begin{tabular}{ccccccc}
\hline $\begin{array}{c}\text { Depth below } \\
\text { measurement polnt } \\
(\mathrm{m})\end{array}$ & \multicolumn{5}{c}{$\begin{array}{c}\text { Computed volumetrlc water content } \\
\left(\mathrm{cm}^{3} / \mathrm{cm}^{3}\right)\end{array}$} \\
\cline { 2 - 7 } & Apr. 2, 1992 & Apr. 8, 1992 & May 7, 1992 & June 22, 1992 & Juiy 27, 1992 & Aug. 26, 1992 \\
\hline 0.7 & 0.231 & 0.206 & 0.182 & 0.123 & 0.108 & 0.122 \\
0.8 & 0.140 & 0.138 & 0.096 & 0.079 & 0.079 & 0.072 \\
0.9 & 0.134 & 0.126 & 0.093 & 0.072 & 0.069 & 0.066 \\
1.0 & 0.142 & 0.128 & 0.096 & 0.072 & 0.069 & 0.070 \\
& & & & & & \\
1.1 & 0.141 & 0.122 & 0.101 & 0.072 & 0.069 & 0.069 \\
1.2 & 0.135 & 0.130 & 0.113 & 0.076 & 0.070 & 0.074 \\
1.3 & 0.153 & 0.139 & 0.126 & 0.090 & 0.087 & 0.081 \\
1.4 & 0.171 & 0.165 & 0.148 & 0.098 & 0.093 & 0.088 \\
1.5 & 0.176 & 0.178 & 0.147 & 0.117 & 0.101 & 0.094 \\
& & & & & & \\
1.6 & 0.171 & 0.157 & 0.144 & 0.119 & 0.100 & 0.099 \\
1.7 & 0.153 & 0.144 & 0.137 & 0.110 & 0.096 & 0.092 \\
1.8 & 0.163 & 0.144 & 0.139 & 0.121 & 0.111 & 0.096 \\
1.9 & 0.159 & 0.154 & 0.137 & 0.123 & 0.114 & 0.108 \\
2.0 & 0.165 & 0.155 & 0.146 & 0.130 & 0.118 & 0.107 \\
& & & & & & \\
2.1 & 0.167 & 0.159 & 0.144 & 0.141 & 0.120 & 0.108 \\
2.2 & 0.161 & 0.156 & 0.135 & 0.133 & 0.118 & 0.101 \\
2.3 & 0.146 & 0.149 & 0.142 & 0.137 & 0.113 & 0.109 \\
2.4 & 0.173 & 0.174 & 0.159 & 0.141 & 0.131 & 0.108 \\
2.5 & 0.185 & 0.179 & 0.171 & 0.134 & 0.118 & 0.100
\end{tabular}


Table 4. Preliminary computed volumetric water content from neutron logging in UE-29 UZN \#91 --Continued

\begin{tabular}{|c|c|c|c|c|c|c|}
\hline \multirow{2}{*}{$\begin{array}{l}\text { Depth below } \\
\text { measurement polnt } \\
\text { (m) }\end{array}$} & \multicolumn{6}{|c|}{$\begin{array}{l}\text { Computed volumetric water content } \\
\qquad\left(\mathrm{cm}^{3} / \mathrm{cm}^{3}\right)\end{array}$} \\
\hline & Apr. 2, 1992 & Apr. 8, 1992 & May 7, 1992 & June 22, 1992 & July 27, 1992 & Aug. 26, 1992 \\
\hline 2.6 & 0.162 & 0.153 & 0.129 & 0.124 & 0.099 & 0.085 \\
\hline 2.7 & 0.127 & 0.122 & 0.112 & 0.098 & 0.084 & 0.072 \\
\hline 2.8 & 0.121 & 0.127 & 0.115 & 0.097 & 0.090 & 0.079 \\
\hline 2.9 & 0.136 & 0.142 & 0.121 & 0.112 & 0.097 & 0.093 \\
\hline 3.0 & 0.141 & 0.153 & 0.136 & 0.117 & 0.106 & 0.100 \\
\hline 3.1 & 0.143 & 0.143 & 0.138 & 0.128 & 0.116 & 0.104 \\
\hline 3.2 & 0.142 & 0.143 & 0.138 & 0.129 & 0.115 & 0.106 \\
\hline 3.3 & 0.149 & 0.158 & 0.158 & 0.135 & 0.128 & 0.114 \\
\hline 3.4 & 0.156 & 0.157 & 0.155 & 0.145 & 0.133 & 0.121 \\
\hline 3.5 & 0.150 & 0.152 & 0.149 & 0.142 & 0.117 & 0.111 \\
\hline 3.6 & 0.133 & 0.135 & 0.129 & 0.116 & 0.109 & 0.099 \\
\hline 3.7 & 0.113 & 0.121 & 0.111 & 0.097 & 0.091 & 0.083 \\
\hline 3.8 & 0.117 & 0.131 & 0.124 & 0.100 & 0.084 & 0.081 \\
\hline 3.9 & 0.141 & 0.157 & 0.147 & 0.127 & 0.090 & 0.078 \\
\hline 4.0 & 0.184 & 0.209 & 0.196 & 0.153 & 0.104 & 0.084 \\
\hline 4.1 & 0.189 & 0.197 & 0.197 & 0.152 & 0.107 & 0.090 \\
\hline 4.2 & 0.160 & 0.174 & 0.158 & 0.135 & 0.111 & 0.093 \\
\hline 4.3 & 0.135 & 0.143 & 0.148 & 0.117 & 0.112 & 0.093 \\
\hline 4.4 & 0.134 & 0.136 & 0.137 & 0.123 & 0.113 & 0.094 \\
\hline 4.5 & 0.155 & 0.157 & 0.157 & 0.142 & 0.111 & 0.103 \\
\hline 4.6 & 0.148 & 0.143 & 0.149 & 0.133 & 0.117 & 0.102 \\
\hline 4.7 & 0.143 & 0.139 & 0.146 & 0.131 & 0.112 & 0.103 \\
\hline 4.8 & 0.141 & 0.135 & 0.149 & 0.132 & 0.109 & 0.104 \\
\hline 4.9 & 0.142 & 0.140 & 0.153 & 0.128 & 0.112 & 0.104 \\
\hline 5.0 & 0.150 & 0.136 & 0.151 & 0.130 & 0.106 & 0.099 \\
\hline 5.3 & 0.137 & 0.130 & 0.141 & 0.134 & 0.104 & 0.094 \\
\hline 5.6 & 0.102 & 0.105 & 0.124 & 0.127 & 0.110 & 0.095 \\
\hline 5.9 & 0.098 & 0.090 & 0.087 & 0.097 & 0.098 & 0.091 \\
\hline 6.2 & 0.086 & 0.078 & 0.083 & 0.082 & 0.076 & 0.082 \\
\hline 6.5 & 0.076 & 0.077 & 0.077 & 0.078 & 0.079 & 0.076 \\
\hline 6.8 & 0.069 & 0.069 & 0.071 & 0.072 & 0.068 & 0.070 \\
\hline 7.1 & 0.065 & 0.069 & 0.069 & 0.069 & 0.068 & 0.070 \\
\hline 7.4 & 0.067 & 0.074 & 0.068 & 0.066 & 0.065 & 0.066 \\
\hline 7.7 & 0.068 & 0.066 & 0.062 & 0.062 & 0.065 & 0.063 \\
\hline 8.0 & 0.078 & 0.077 & 0.075 & 0.075 & 0.080 & 0.076 \\
\hline
\end{tabular}


Table 4. Preliminary computed volumetric water content from neutron logging in UE-29 UZN \#91 --Continued

\begin{tabular}{|c|c|c|c|c|c|c|}
\hline \multirow{2}{*}{$\begin{array}{l}\text { Depth below } \\
\text { measurement point } \\
(m)\end{array}$} & \multicolumn{6}{|c|}{$\begin{array}{l}\text { Computed volumetric water content } \\
\qquad\left(\mathrm{cm}^{3} / \mathrm{cm}^{3}\right)\end{array}$} \\
\hline & Apr. 2, 1992 & Apr. 8, 1992 & May 7, 1992 & June 22, 1992 & July 27, 1992 & Aug. 26, 1992 \\
\hline 8.3 & 0.070 & 0.071 & 0.074 & 0.067 & 0.071 & 0.067 \\
\hline 8.6 & 0.072 & 0.074 & 0.073 & 0.074 & 0.071 & 0.068 \\
\hline 8.9 & 0.091 & 0.085 & 0.088 & 0.088 & 0.091 & 0.090 \\
\hline 9.2 & 0.086 & 0.084 & 0.092 & 0.085 & 0.081 & 0.083 \\
\hline 9.5 & 0.089 & 0.085 & 0.084 & 0.089 & 0.092 & 0.086 \\
\hline 9.8 & 0.124 & 0.121 & 0.119 & 0.120 & 0.118 & 0.117 \\
\hline 10.1 & 0.087 & 0.093 & 0.087 & 0.089 & 0.084 & 0.091 \\
\hline 10.4 & 0.099 & 0.100 & 0.101 & 0.096 & 0.097 & 0.096 \\
\hline 10.7 & 0.122 & 0.118 & 0.120 & 0.114 & 0.123 & 0.121 \\
\hline 11.0 & 0.103 & 0.098 & 0.106 & 0.102 & 0.094 & 0.100 \\
\hline 11.3 & 0.091 & 0.097 & 0.096 & 0.097 & 0.094 & 0.097 \\
\hline 11.6 & 0.102 & 0.107 & 0.108 & 0.101 & 0.100 & 0.103 \\
\hline 11.9 & 0.153 & 0.156 & 0.158 & 0.156 & 0.153 & 0.156 \\
\hline 12.2 & 0.126 & 0.125 & 0.129 & 0.117 & 0.126 & 0.134 \\
\hline 12.5 & 0.175 & 0.184 & 0.163 & 0.160 & 0.177 & 0.177 \\
\hline 12.8 & 0.161 & 0.166 & 0.158 & 0.166 & 0.159 & 0.156 \\
\hline 13.1 & 0.148 & 0.147 & 0.138 & 0.145 & 0.146 & 0.154 \\
\hline 13.4 & 0.142 & 0.140 & 0.136 & 0.142 & 0.126 & 0.125 \\
\hline 13.7 & 0.142 & 0.138 & 0.150 & 0.139 & 0.144 & 0.144 \\
\hline 14.0 & 0.135 & 0.131 & 0.128 & 0.131 & 0.121 & 0.123 \\
\hline 14.3 & 0.099 & 0.098 & 0.100 & 0.103 & 0.093 & 0.100 \\
\hline 14.6 & 0.086 & 0.094 & 0.095 & 0.086 & 0.091 & 0.087 \\
\hline 14.9 & 0.158 & 0.145 & 0.152 & 0.150 & 0.165 & 0.150 \\
\hline 15.2 & 0.177 & 0.191 & 0.180 & 0.180 & 0.183 & 0.183 \\
\hline 15.5 & 0.178 & 0.179 & 0.179 & 0.179 & 0.180 & 0.180 \\
\hline 15.8 & 0.171 & 0.167 & 0.163 & 0.171 & 0.170 & 0.173 \\
\hline 16.1 & 0.170 & 0.168 & - & 0.179 & 0.167 & 0.168 \\
\hline
\end{tabular}


Table 5. Preliminary computed volumetric water content from neutron logging in UE-29 UZN \#92

[m, meter; $\mathrm{cm}^{3}$, cubic centimeters; measurement point is top of casing after cap is removed]

\begin{tabular}{|c|c|c|c|c|c|c|c|}
\hline \multirow{2}{*}{$\begin{array}{l}\text { Depth below } \\
\text { measurement } \\
\text { point } \\
\text { (m) }\end{array}$} & \multicolumn{7}{|c|}{$\begin{array}{l}\text { Computed volumetric water content } \\
\qquad\left(\mathrm{cm}^{3} / \mathrm{cm}^{3}\right)\end{array}$} \\
\hline & Oct. 29, 1991 & Dec. 3, 1991 & Jan. 28, 1992 & Feb. 15, 1992 & Feb. 21, 1992 & Feb. 25, 1992 & Mar. 6, 1992 \\
\hline 0.7 & 0.067 & 0.057 & 0.114 & 0.141 & 0.133 & 0.129 & 0.139 \\
\hline 0.8 & 0.066 & 0.066 & 0.100 & 0.119 & 0.125 & 0.120 & 0.117 \\
\hline 0.9 & 0.068 & 0.066 & 0.094 & 0.120 & 0.119 & 0.118 & 0.121 \\
\hline 1.0 & 0.062 & 0.067 & 0.084 & 0.124 & 0.118 & 0.116 & 0.120 \\
\hline 1.1 & 0.076 & 0.071 & 0.082 & 0.137 & 0.126 & 0.127 & 0.127 \\
\hline 1.2 & 0.074 & 0.076 & 0.082 & 0.148 & 0.135 & 0.142 & 0.145 \\
\hline 1.3 & 0.080 & 0.080 & 0.079 & 0.147 & 0.149 & 0.138 & 0.140 \\
\hline 1.4 & 0.078 & 0.082 & 0.081 & 0.152 & 0.147 & 0.146 & 0.147 \\
\hline 1.5 & 0.072 & 0.072 & 0.073 & 0.139 & 0.145 & 0.137 & 0.143 \\
\hline 1.6 & 0.070 & 0.062 & 0.066 & 0.121 & 0.133 & 0.125 & 0.123 \\
\hline 1.7 & 0.063 & 0.066 & 0.069 & 0.105 & 0.117 & 0.118 & 0.111 \\
\hline 1.8 & 0.071 & 0.074 & 0.073 & 0.123 & 0.123 & 0.120 & 0.116 \\
\hline 1.9 & 0.079 & 0.085 & 0.082 & 0.138 & 0.141 & 0.139 & 0.140 \\
\hline 2.0 & 0.083 & 0.086 & 0.086 & 0.132 & 0.137 & 0.139 & 0.141 \\
\hline 2.1 & 0.090 & 0.092 & 0.093 & 0.151 & 0.147 & 0.150 & 0.143 \\
\hline 2.2 & 0.108 & 0.101 & 0.103 & 0.171 & 0.165 & 0.168 & 0.167 \\
\hline 2.3 & 0.106 & 0.108 & 0.100 & 0.178 & 0.175 & 0.185 & 0.171 \\
\hline 2.4 & 0.109 & 0.108 & 0.107 & 0.175 & 0.178 & 0.188 & 0.178 \\
\hline 2.5 & 0.113 & 0.112 & 0.110 & 0.185 & 0.178 & 0.184 & 0.186 \\
\hline 2.6 & 0.118 & 0.117 & 0.117 & 0.197 & 0.194 & 0.197 & 0.189 \\
\hline 2.7 & 0.121 & 0.129 & 0.122 & 0.203 & 0.205 & 0.201 & 0.197 \\
\hline 2.8 & 0.127 & 0.127 & 0.128 & 0.207 & 0.212 & 0.196 & 0.199 \\
\hline 2.9 & 0.120 & 0.117 & 0.122 & 0.186 & 0.179 & 0.182 & 0.183 \\
\hline 3.0 & 0.110 & 0.102 & 0.110 & 0.181 & 0.184 & 0.174 & 0.181 \\
\hline 3.1 & 0.112 & 0.104 & 0.107 & 0.181 & 0.183 & 0.170 & 0.173 \\
\hline 3.2 & 0.105 & 0.105 & 0.108 & 0.184 & 0.179 & 0.184 & 0.176 \\
\hline 3.3 & 0.102 & 0.104 & 0.104 & 0.178 & 0.171 & 0.167 & 0.167 \\
\hline 3.4 & 0.092 & 0.097 & 0.103 & 0.165 & 0.156 & 0.161 & 0.160 \\
\hline 3.5 & 0.096 & 0.095 & 0.093 & 0.147 & 0.144 & 0.157 & 0.151 \\
\hline 3.6 & 0.082 & 0.084 & 0.081 & 0.125 & 0.128 & 0.130 & 0.130 \\
\hline 3.7 & 0.082 & 0.084 & 0.086 & 0.129 & 0.134 & 0.139 & 0.133 \\
\hline 3.8 & 0.082 & 0.085 & 0.085 & 0.140 & 0.137 & 0.135 & 0.133 \\
\hline 3.9 & 0.081 & 0.088 & 0.083 & 0.134 & 0.134 & 0.130 & 0.133 \\
\hline 4.0 & 0.088 & 0.091 & 0.085 & 0.140 & 0.135 & 0.135 & 0.139 \\
\hline
\end{tabular}


Table 5. Preliminary computed volumetric water content from neutron logging in UE-29 UZN \#92 --Continued

\begin{tabular}{|c|c|c|c|c|c|c|c|}
\hline \multirow{2}{*}{$\begin{array}{l}\text { Depth below } \\
\text { measurement } \\
\text { point } \\
\text { (m) }\end{array}$} & \multicolumn{7}{|c|}{$\begin{array}{l}\text { Computed volumetric water content } \\
\qquad\left(\mathrm{cm}^{3} / \mathrm{cm}^{3}\right)\end{array}$} \\
\hline & Oct. 29, 1991 & Dec. 3, 1991 & Jan. 28, 1992 & Feb. 15, 1992 & Feb. 21, 1992 & Feb. 25, 1992 & Mar. 6, 1992 \\
\hline 4.1 & 0.092 & 0.091 & 0.090 & 0.134 & 0.136 & 0.136 & 0.136 \\
\hline 4.2 & 0.086 & 0.090 & 0.090 & 0.139 & 0.137 & 0.139 & 0.137 \\
\hline 4.3 & 0.090 & 0.092 & 0.094 & 0.141 & 0.139 & 0.134 & 0.138 \\
\hline 4.4 & 0.096 & 0.091 & 0.095 & 0.153 & 0.142 & 0.135 & 0.135 \\
\hline 4.5 & 0.093 & 0.095 & 0.094 & 0.151 & 0.139 & 0.139 & 0.150 \\
\hline 4.6 & 0.094 & 0.099 & 0.099 & 0.145 & 0.134 & 0.137 & 0.140 \\
\hline 4.7 & 0.097 & 0.093 & 0.103 & 0.140 & 0.139 & 0.138 & 0.133 \\
\hline 4.8 & 0.094 & 0.095 & 0.099 & 0.130 & 0.132 & 0.135 & 0.131 \\
\hline 4.9 & 0.089 & 0.089 & 0.094 & 0.120 & 0.130 & 0.126 & 0.121 \\
\hline 5.0 & 0.095 & 0.096 & 0.102 & 0.122 & 0.127 & 0.123 & 0.123 \\
\hline 5.3 & 0.077 & 0.081 & 0.078 & 0.088 & 0.087 & 0.090 & 0.091 \\
\hline 5.6 & 0.106 & 0.112 & 0.112 & 0.114 & 0.114 & 0.110 & 0.113 \\
\hline 5.9 & 0.127 & 0.129 & 0.122 & 0.120 & 0.126 & 0.120 & 0.119 \\
\hline 6.2 & 0.126 & 0.128 & 0.122 & 0.126 & 0.116 & 0.124 & 0.129 \\
\hline 6.5 & 0.119 & 0.126 & 0.117 & 0.112 & 0.122 & 0.121 & 0.121 \\
\hline 6.8 & 0.108 & 0.108 & 0.106 & 0.107 & 0.106 & 0.099 & 0.104 \\
\hline 7.1 & 0.112 & 0.115 & 0.117 & 0.119 & 0.123 & 0.118 & 0.120 \\
\hline 7.4 & 0.125 & 0.131 & 0.130 & 0.132 & 0.130 & 0.132 & 0.122 \\
\hline 7.7 & 0.129 & 0.124 & 0.118 & 0.132 & 0.124 & 0.127 & 0.130 \\
\hline 8.0 & 0.128 & 0.128 & 0.122 & 0.124 & 0.125 & 0.123 & 0.128 \\
\hline 8.3 & 0.135 & 0.136 & 0.138 & 0.129 & 0.135 & 0.138 & 0.137 \\
\hline 8.6 & 0.126 & 0.115 & 0.123 & 0.119 & 0.127 & 0.116 & 0.113 \\
\hline 8.9 & 0.113 & 0.114 & 0.117 & 0.117 & 0.111 & 0.112 & 0.107 \\
\hline 9.2 & 0.104 & 0.123 & 0.116 & 0.110 & 0.117 & 0.112 & 0.110 \\
\hline 9.5 & 0.119 & 0.123 & 0.123 & 0.121 & 0.121 & 0.126 & 0.125 \\
\hline 9.8 & 0.117 & 0.117 & 0.116 & 0.112 & 0.116 & 0.118 & 0.113 \\
\hline 10.1 & 0.108 & 0.110 & 0.108 & 0.103 & 0.108 & 0.113 & 0.103 \\
\hline 10.4 & 0.114 & 0.123 & 0.120 & 0.123 & 0.116 & 0.120 & 0.118 \\
\hline 10.7 & 0.142 & 0.143 & 0.142 & 0.138 & 0.142 & 0.136 & 0.139 \\
\hline 11.0 & 0.120 & 0.116 & 0.118 & 0.114 & 0.117 & 0.118 & 0.127 \\
\hline 11.3 & 0.101 & 0.102 & 0.107 & 0.106 & 0.109 & 0.104 & 0.106 \\
\hline 11.6 & 0.124 & 0.127 & 0.125 & 0.120 & 0.130 & 0.128 & 0.128 \\
\hline 11.9 & 0.132 & 0.135 & 0.133 & 0.132 & 0.137 & 0.134 & 0.131 \\
\hline 12.2 & 0.114 & 0.113 & 0.118 & 0.109 & 0.119 & 0.108 & 0.116 \\
\hline 12.5 & 0.104 & 0.105 & 0.101 & 0.102 & 0.103 & 0.098 & 0.101 \\
\hline
\end{tabular}


Table 5. Preliminary computed volumetric water content from neutron logging in UE-29 UZN \#92 --Continued

\begin{tabular}{|c|c|c|c|c|c|c|c|}
\hline \multirow{2}{*}{$\begin{array}{l}\text { Depth below } \\
\text { measurement } \\
\text { point } \\
\text { (m) }\end{array}$} & \multicolumn{7}{|c|}{$\begin{array}{l}\text { Computed volumetric water content } \\
\qquad\left(\mathrm{cm}^{3} / \mathrm{cm}^{3}\right)\end{array}$} \\
\hline & Oct. 29, 1991 & Dec. 3, 1991 & Jan. 28, 1992 & Feb. 15, 1992 & Feb. 21, 1992 & Feb. 25, 1992 & Mar. 6, 1992 \\
\hline 12.8 & 0.126 & 0.124 & 0.122 & 0.127 & 0.129 & 0.124 & 0.122 \\
\hline 13.1 & 0.136 & 0.144 & 0.140 & 0.139 & 0.142 & 0.135 & 0.141 \\
\hline 13.4 & 0.134 & 0.132 & 0.130 & 0.131 & 0.131 & 0.131 & 0.131 \\
\hline 13.7 & 0.121 & 0.125 & 0.125 & 0.124 & 0.124 & 0.131 & 0.125 \\
\hline 14.0 & 0.109 & 0.105 & 0.106 & 0.113 & 0.110 & 0.114 & 0.106 \\
\hline 14.3 & 0.110 & 0.103 & 0.111 & 0.112 & 0.111 & 0.105 & 0.108 \\
\hline 14.6 & 0.122 & 0.125 & 0.123 & 0.129 & 0.123 & 0.127 & 0.123 \\
\hline 14.9 & 0.126 & 0.126 & 0.130 & 0.118 & 0.135 & 0.133 & 0.133 \\
\hline 15.2 & 0.120 & 0.121 & 0.116 & 0.117 & 0.119 & 0.113 & 0.118 \\
\hline 15.5 & 0.108 & 0.109 & 0.108 & 0.107 & 0.105 & 0.108 & 0.101 \\
\hline 15.8 & 0.134 & 0.143 & 0.142 & 0.141 & 0.138 & 0.135 & 0.142 \\
\hline 16.1 & 0.126 & 0.129 & 0.125 & 0.135 & 0.126 & 0.127 & 0.130 \\
\hline 16.4 & 0.124 & 0.121 & 0.128 & 0.122 & 0.125 & 0.116 & 0.115 \\
\hline 16.7 & 0.122 & 0.126 & 0.121 & 0.123 & 0.123 & 0.135 & 0.131 \\
\hline 17.0 & 0.134 & 0.131 & 0.135 & 0.130 & 0.134 & 0.131 & 0.138 \\
\hline 17.3 & 0.136 & 0.138 & 0.140 & 0.132 & 0.125 & 0.128 & 0.129 \\
\hline 17.6 & - & 0.140 & 0.140 & 0.134 & 0.133 & 0.132 & 0.134 \\
\hline 17.9 & 0.125 & 0.123 & 0.129 & 0.127 & 0.136 & 0.131 & 0.120 \\
\hline 18.2 & 0.118 & 0.121 & 0.120 & 0.126 & 0.126 & 0.127 & 0.121 \\
\hline 18.5 & 0.175 & 0.166 & 0.158 & 0.174 & 0.165 & 0.163 & 0.169 \\
\hline 18.8 & 0.181 & 0.184 & 0.185 & 0.186 & 0.172 & 0.176 & 0.183 \\
\hline 19.1 & 0.165 & 0.158 & 0.174 & 0.167 & 0.183 & 0.174 & 0.164 \\
\hline 19.4 & 0.145 & 0.144 & 0.128 & 0.146 & 0.141 & 0.138 & 0.146 \\
\hline
\end{tabular}

\begin{tabular}{|c|c|c|c|c|c|c|c|}
\hline \multirow{2}{*}{$\begin{array}{l}\text { Depth below } \\
\text { measurement } \\
\text { point } \\
\text { (m) }\end{array}$} & \multicolumn{7}{|c|}{$\begin{array}{l}\text { Computed volumetric water content } \\
\qquad\left(\mathrm{cm}^{3} / \mathrm{cm}^{3}\right)\end{array}$} \\
\hline & Mar. 11, 1992 & Apr. 2, 1992 & Apr. 8, 1992 & May 7, 1992 & June 22, 1992 & July 27, 1992 & Aug. 26, 1992 \\
\hline 0.7 & 0.143 & 0.146 & 0.128 & 0.087 & 0.058 & 0.053 & 0.052 \\
\hline 0.8 & 0.120 & 0.129 & 0.106 & 0.068 & 0.062 & 0.063 & 0.058 \\
\hline 0.9 & 0.115 & 0.122 & 0.112 & 0.070 & 0.066 & 0.065 & 0.068 \\
\hline 1.0 & 0.113 & 0.117 & 0.111 & 0.079 & 0.069 & 0.069 & 0.065 \\
\hline 1.1 & 0.123 & 0.126 & 0.123 & 0.090 & 0.075 & 0.074 & 0.068 \\
\hline 1.2 & 0.141 & 0.147 & 0.143 & 0.112 & 0.087 & 0.080 & 0.081 \\
\hline 1.3 & 0.146 & 0.157 & 0.157 & 0.126 & 0.088 & 0.080 & 0.083 \\
\hline 1.4 & 0.147 & 0.157 & 0.143 & 0.129 & 0.089 & 0.083 & 0.083 \\
\hline
\end{tabular}


Table 5. Preliminary computed volumetric water content from neutron logging in UE-29 UZN \#92 --Continued

\begin{tabular}{|c|c|c|c|c|c|c|c|}
\hline \multirow{2}{*}{$\begin{array}{l}\text { Depth below } \\
\text { measurement } \\
\text { point } \\
\text { (m) }\end{array}$} & \multicolumn{7}{|c|}{$\begin{array}{l}\text { Computed volumetric water content } \\
\qquad\left(\mathrm{cm}^{3} / \mathrm{cm}^{3}\right)\end{array}$} \\
\hline & Mar. 11, 1992 & Apr. 2, 1992 & Apr. 8, 1992 & May 7, 1992 & June 22, 1992 & July 27, 1992 & Aug. 26, 1992 \\
\hline 1.5 & 0.142 & 0.151 & 0.144 & 0.123 & 0.085 & 0.077 & 0.079 \\
\hline 1.6 & 0.127 & 0.140 & 0.130 & 0.100 & 0.078 & 0.073 & 0.073 \\
\hline 1.7 & 0.120 & 0.124 & 0.123 & 0.106 & 0.085 & 0.071 & 0.077 \\
\hline 1.8 & 0.122 & 0.133 & 0.124 & 0.114 & 0.090 & 0.079 & 0.075 \\
\hline 1.9 & 0.143 & 0.152 & 0.148 & 0.128 & 0.107 & 0.097 & 0.089 \\
\hline 2.0 & 0.140 & 0.148 & 0.133 & 0.133 & 0.107 & 0.093 & 0.093 \\
\hline 2.1 & 0.152 & 0.160 & 0.155 & 0.150 & 0.121 & 0.104 & 0.097 \\
\hline 2.2 & 0.170 & 0.169 & 0.177 & 0.164 & 0.128 & 0.115 & 0.110 \\
\hline 2.3 & 0.176 & 0.189 & 0.187 & 0.174 & 0.141 & 0.118 & 0.114 \\
\hline 2.4 & 0.171 & 0.196 & 0.185 & 0.173 & 0.156 & 0.132 & 0.119 \\
\hline 2.5 & 0.187 & 0.192 & 0.188 & 0.188 & 0.165 & 0.134 & 0.126 \\
\hline 2.6 & 0.198 & 0.207 & 0.190 & 0.185 & 0.170 & 0.148 & 0.129 \\
\hline 2.7 & 0.202 & 0.216 & 0.212 & 0.200 & 0.190 & 0.164 & 0.141 \\
\hline 2.8 & 0.212 & 0.218 & 0.200 & 0.208 & 0.195 & 0.184 & 0.160 \\
\hline 2.9 & 0.189 & 0.192 & 0.190 & 0.187 & 0.181 & 0.167 & 0.144 \\
\hline 3.0 & 0.177 & 0.178 & 0.187 & 0.174 & 0.171 & 0.169 & 0.142 \\
\hline 3.1 & 0.170 & 0.179 & 0.181 & 0.170 & 0.163 & 0.167 & 0.144 \\
\hline 3.2 & 0.162 & 0.181 & 0.187 & 0.173 & 0.160 & 0.148 & 0.146 \\
\hline 3.3 & 0.162 & 0.163 & 0.166 & 0.164 & 0.157 & 0.154 & 0.146 \\
\hline 3.4 & 0.156 & 0.152 & 0.166 & 0.153 & 0.155 & 0.144 & 0.150 \\
\hline 3.5 & 0.147 & 0.154 & 0.160 & 0.150 & 0.139 & 0.140 & 0.141 \\
\hline 3.6 & 0.128 & 0.131 & 0.136 & 0.132 & 0.132 & 0.122 & 0.120 \\
\hline 3.7 & 0.129 & 0.137 & 0.133 & 0.136 & 0.125 & 0.132 & 0.119 \\
\hline 3.8 & 0.141 & 0.142 & 0.139 & 0.138 & 0.131 & 0.128 & 0.124 \\
\hline 3.9 & 0.133 & 0.138 & 0.139 & 0.135 & 0.132 & 0.132 & 0.127 \\
\hline 4.0 & 0.143 & 0.139 & 0.135 & 0.146 & 0.140 & 0.130 & 0.132 \\
\hline 4.1 & 0.137 & 0.143 & 0.136 & 0.145 & 0.144 & 0.137 & 0.132 \\
\hline 4.2 & 0.139 & 0.140 & 0.146 & 0.143 & 0.142 & 0.133 & 0.135 \\
\hline 4.3 & 0.145 & 0.139 & 0.146 & 0.137 & 0.145 & 0.135 & 0.136 \\
\hline 4.4 & 0.146 & 0.136 & 0.147 & 0.144 & 0.148 & 0.142 & 0.142 \\
\hline 4.5 & 0.140 & 0.144 & 0.158 & 0.146 & 0.140 & 0.148 & 0.133 \\
\hline 4.6 & 0.141 & 0.149 & 0.146 & 0.140 & 0.150 & 0.134 & 0.143 \\
\hline 4.7 & 0.142 & 0.151 & 0.158 & 0.148 & 0.144 & 0.147 & 0.138 \\
\hline 4.8 & 0.131 & 0.139 & 0.139 & 0.145 & 0.142 & 0.135 & 0.128 \\
\hline 4.9 & 0.120 & 0.126 & 0.133 & 0.135 & 0.134 & 0.130 & 0.121 \\
\hline 5.0 & 0.130 & 0.139 & 0.133 & 0.143 & 0.137 & 0.136 & 0.133 \\
\hline
\end{tabular}


Table 5. Preliminary computed volumetric water content from neutron logging in UE-29 UZN \#92 --Continued

\begin{tabular}{|c|c|c|c|c|c|c|c|}
\hline \multirow{2}{*}{$\begin{array}{l}\text { Depth below } \\
\text { measurement } \\
\text { point } \\
\text { (m) }\end{array}$} & \multicolumn{7}{|c|}{$\begin{array}{l}\text { Computed volumetric water content } \\
\qquad\left(\mathrm{cm}^{3} / \mathrm{cm}^{3}\right)\end{array}$} \\
\hline & Mar. 11, 1992 & Apr. 2, 1992 & Apr. 8, 1992 & May 7, 1992 & June 22, 1992 & July 27, 1992 & Aug. 26, 1992 \\
\hline 5.3 & 0.092 & 0.113 & 0.120 & 0.123 & 0.115 & 0.112 & 0.103 \\
\hline 5.6 & 0.115 & 0.120 & 0.125 & 0.120 & 0.126 & 0.128 & 0.123 \\
\hline 5.9 & 0.121 & 0.129 & 0.127 & 0.127 & 0.138 & 0.128 & 0.138 \\
\hline 6.2 & 0.126 & 0.125 & 0.117 & 0.118 & 0.130 & 0.136 & 0.135 \\
\hline 6.5 & 0.118 & 0.119 & 0.127 & 0.120 & 0.123 & 0.120 & 0.119 \\
\hline 6.8 & 0.112 & 0.111 & 0.105 & 0.114 & 0.108 & 0.105 & 0.111 \\
\hline 7.1 & 0.116 & 0.122 & 0.126 & 0.121 & 0.118 & 0.121 & 0.120 \\
\hline 7.4 & 0.134 & 0.129 & 0.131 & 0.130 & 0.137 & 0.127 & 0.127 \\
\hline 7.7 & 0.119 & 0.123 & 0.123 & 0.121 & 0.125 & 0.126 & 0.126 \\
\hline 8.0 & 0.121 & 0.124 & 0.123 & 0.124 & 0.127 & 0.118 & 0.123 \\
\hline 8.3 & 0.135 & 0.136 & 0.136 & 0.131 & 0.132 & 0.137 & 0.128 \\
\hline 8.6 & 0.123 & 0.123 & 0.118 & 0.120 & 0.116 & 0.122 & 0.120 \\
\hline 8.9 & 0.110 & 0.114 & 0.105 & 0.109 & 0.115 & 0.110 & 0.108 \\
\hline 9.2 & 0.113 & 0.116 & 0.110 & 0.117 & 0.123 & 0.109 & 0.115 \\
\hline 9.5 & 0.114 & 0.120 & 0.117 & 0.116 & 0.121 & 0.123 & 0.119 \\
\hline 9.8 & 0.116 & 0.113 & 0.113 & 0.114 & 0.110 & 0.117 & 0.118 \\
\hline 10.1 & 0.109 & 0.109 & 0.108 & 0.106 & 0.108 & 0.104 & 0.106 \\
\hline 10.4 & 0.119 & 0.117 & 0.126 & 0.123 & 0.121 & 0.121 & 0.129 \\
\hline 10.7 & 0.136 & 0.136 & 0.140 & 0.133 & 0.139 & 0.139 & 0.141 \\
\hline 11.0 & 0.113 & 0.119 & 0.113 & 0.122 & 0.125 & 0.117 & 0.111 \\
\hline 11.3 & 0.104 & 0.104 & 0.104 & 0.102 & 0.105 & 0.104 & 0.101 \\
\hline 11.6 & 0.126 & 0.125 & 0.128 & 0.129 & 0.125 & 0.123 & 0.129 \\
\hline 11.9 & 0.142 & 0.137 & 0.130 & 0.139 & 0.129 & 0.131 & 0.130 \\
\hline 12.2 & 0.114 & 0.119 & 0.113 & 0.115 & 0.108 & 0.117 & 0.107 \\
\hline 12.5 & 0.106 & 0.104 & 0.109 & 0.103 & 0.107 & 0.106 & 0.102 \\
\hline 12.8 & 0.123 & 0.126 & 0.121 & 0.122 & 0.125 & 0.129 & 0.139 \\
\hline 13.1 & 0.141 & 0.140 & 0.145 & 0.147 & 0.146 & 0.143 & 0.147 \\
\hline 13.4 & 0.130 & 0.129 & 0.126 & 0.132 & 0.136 & 0.140 & 0.132 \\
\hline 13.7 & 0.125 & 0.118 & 0.119 & 0.129 & 0.124 & 0.121 & 0.118 \\
\hline 14.0 & 0.114 & 0.113 & 0.111 & 0.115 & 0.115 & 0.116 & 0.110 \\
\hline 14.3 & 0.114 & 0.106 & 0.111 & 0.109 & 0.109 & 0.104 & 0.111 \\
\hline 14.6 & 0.121 & 0.129 & 0.122 & 0.129 & 0.124 & 0.135 & 0.128 \\
\hline 14.9 & 0.136 & 0.129 & 0.128 & 0.129 & 0.129 & 0.122 & 0.129 \\
\hline 15.2 & 0.119 & 0.108 & 0.120 & 0.113 & 0.120 & 0.111 & 0.114 \\
\hline 15.5 & 0.102 & 0.102 & 0.108 & 0.106 & 0.105 & 0.109 & 0.105 \\
\hline
\end{tabular}


Table 5. Preliminary computed volumetric water content from neutron logging in UE-29 UZN \#92 --Continued

\begin{tabular}{|c|c|c|c|c|c|c|c|}
\hline \multirow{2}{*}{$\begin{array}{l}\text { Depth below } \\
\text { measurement } \\
\text { point } \\
\text { (m) }\end{array}$} & \multicolumn{7}{|c|}{$\begin{array}{l}\text { Computed volumetric water content } \\
\qquad\left(\mathrm{cm}^{3} / \mathrm{cm}^{3}\right)\end{array}$} \\
\hline & Mar. 11, 1992 & Apr. 2, 1992 & Apr. 8, 1992 & May 7, 1992 & June 22, 1992 & July 27, 1992 & Aug. 26, 1992 \\
\hline 15.8 & 0.136 & 0.142 & 0.142 & 0.142 & 0.143 & 0.142 & 0.140 \\
\hline 16.1 & 0.126 & 0.126 & 0.122 & 0.119 & 0.127 & 0.121 & 0.124 \\
\hline 16.4 & 0.121 & 0.118 & 0.119 & 0.130 & 0.124 & 0.125 & 0.129 \\
\hline 16.7 & 0.125 & 0.122 & 0.125 & 0.128 & 0.130 & 0.131 & 0.127 \\
\hline 17.0 & 0.135 & 0.141 & 0.133 & 0.139 & 0.131 & 0.133 & 0.128 \\
\hline 17.3 & 0.132 & 0.130 & 0.132 & 0.134 & 0.132 & 0.131 & 0.131 \\
\hline 17.6 & 0.135 & 0.131 & 0.138 & 0.132 & 0.132 & 0.132 & 0.126 \\
\hline 17.9 & 0.133 & 0.127 & 0.128 & 0.124 & 0.124 & 0.121 & 0.120 \\
\hline 18.2 & 0.121 & 0.128 & 0.116 & 0.123 & 0.120 & 0.117 & 0.118 \\
\hline 18.5 & 0.169 & 0.167 & 0.171 & 0.168 & 0.169 & 0.173 & 0.177 \\
\hline 18.8 & 0.184 & 0.182 & 0.196 & 0.175 & 0.172 & 0.183 & 0.186 \\
\hline 19.1 & 0.170 & 0.170 & 0.169 & 0.166 & 0.174 & 0.158 & 0.153 \\
\hline 19.4 & 0.128 & 0.141 & 0.143 & 0.131 & 0.137 & 0.136 & 0.132 \\
\hline
\end{tabular}




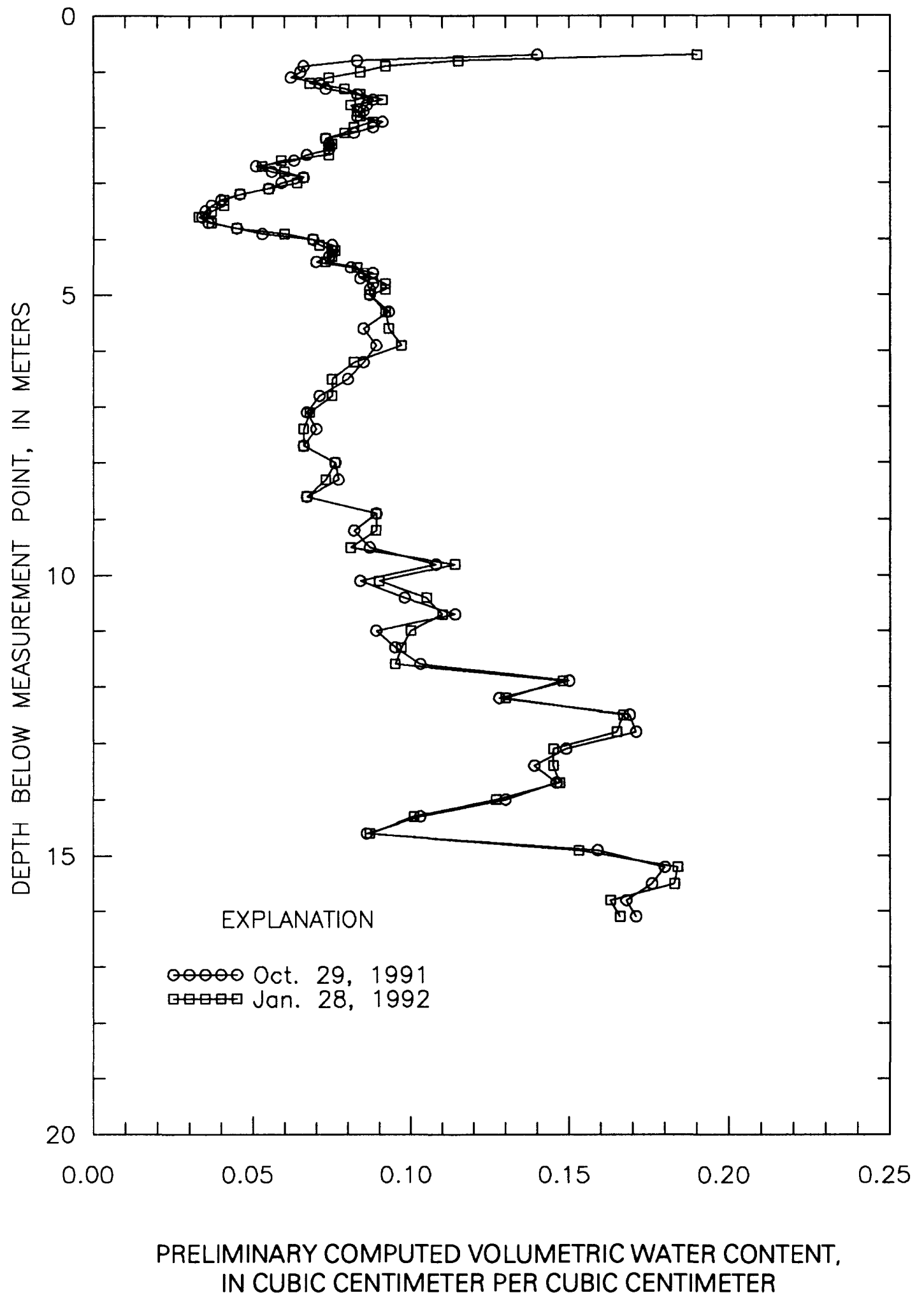

Figure 6. Preliminary computed volumetric water-content profiles for UE-29 UZN \#91 for Oct. 29, 1991 and Jan. 28, 1992. 


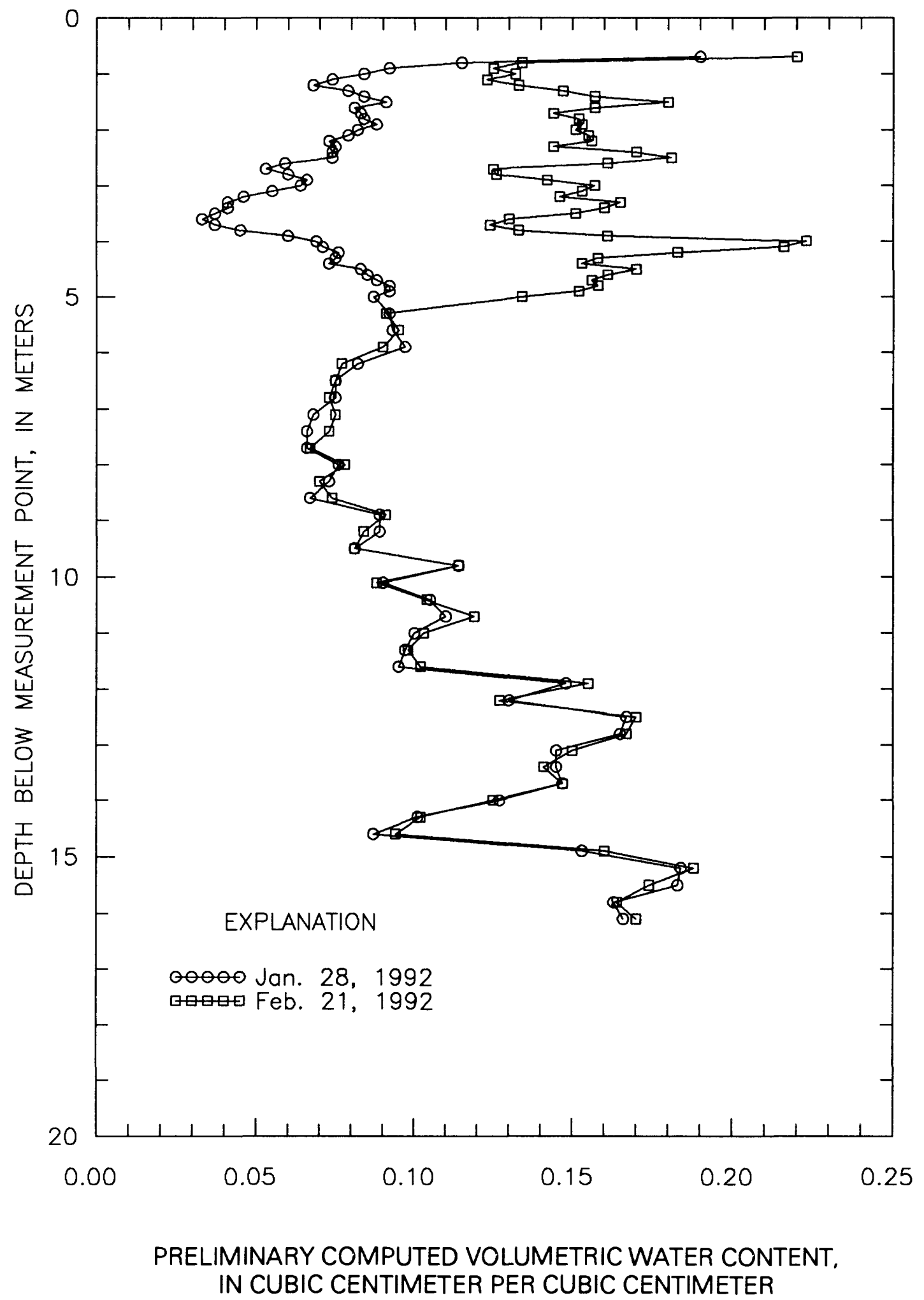

Figure 7. Preliminary computed volumetric water-content profiles for UE-29 UZN \#91 for Jan. 28, 1992 and Feb. 21, 1992. 


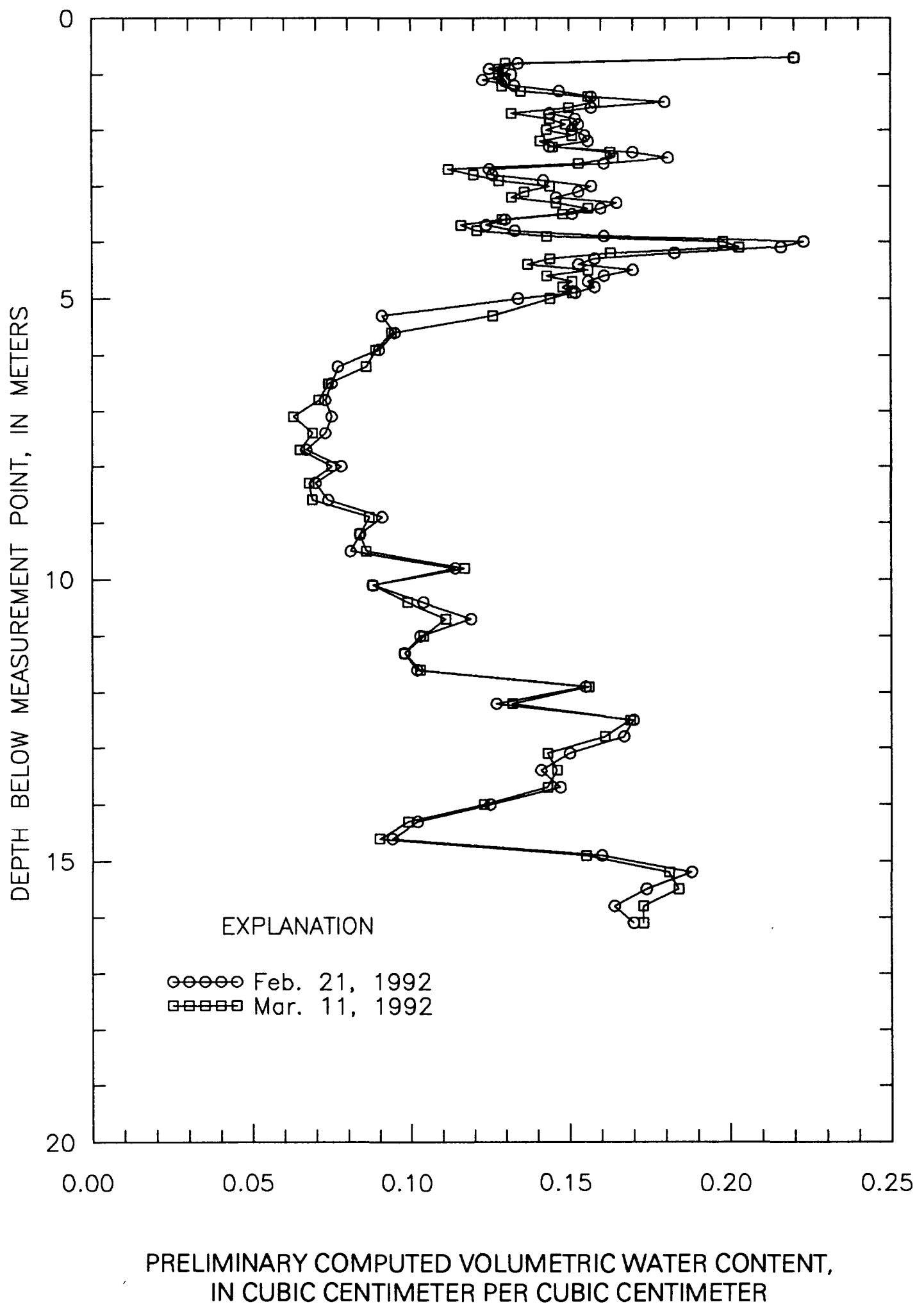

Figure 8. Preliminary computed volumetric water-content profiles for UE-29 UZN \#91 for Feb. 21, 1992 and Mar. 11, 1992. 


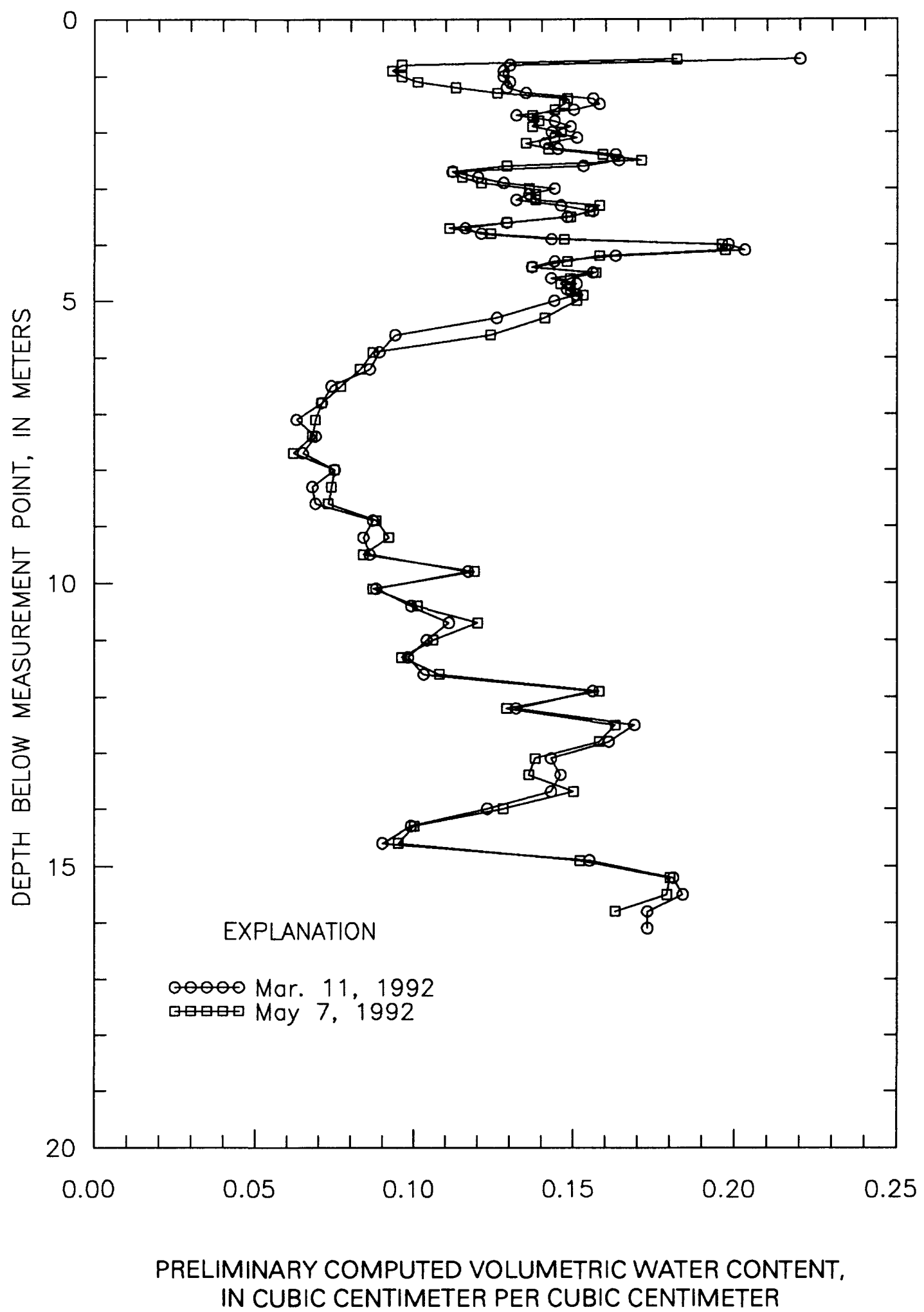

Figure 9. Preliminary computed volumetric water-content profiles for UE-29 UZN \#91 for Mar. 11, 1992 and May 7, 1992. 


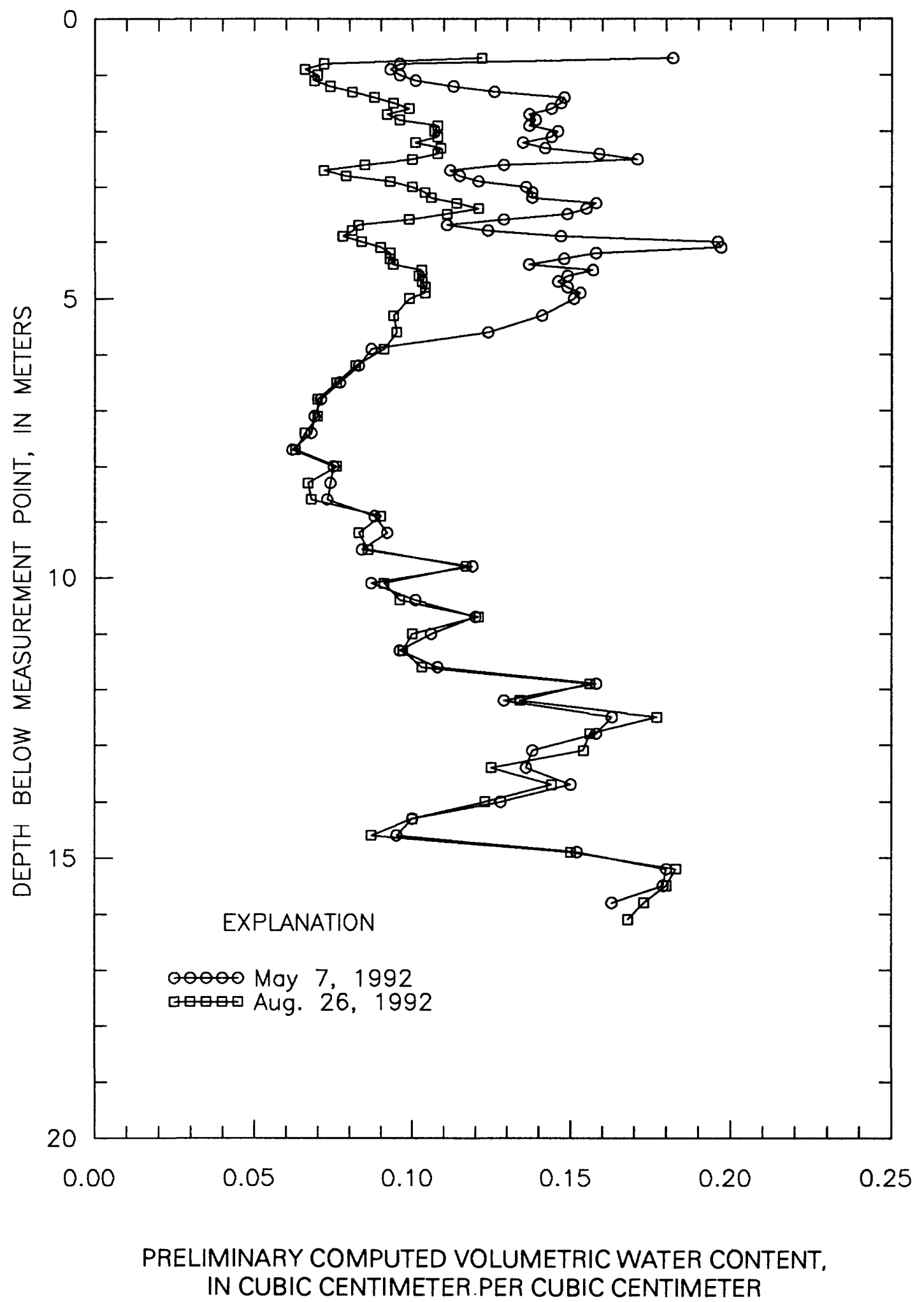

Figure 10. Preliminary computed volumetric water-content profiles for UE-29 UZN \#91 for May 7, 1992 and Aug. 26, 1992. 


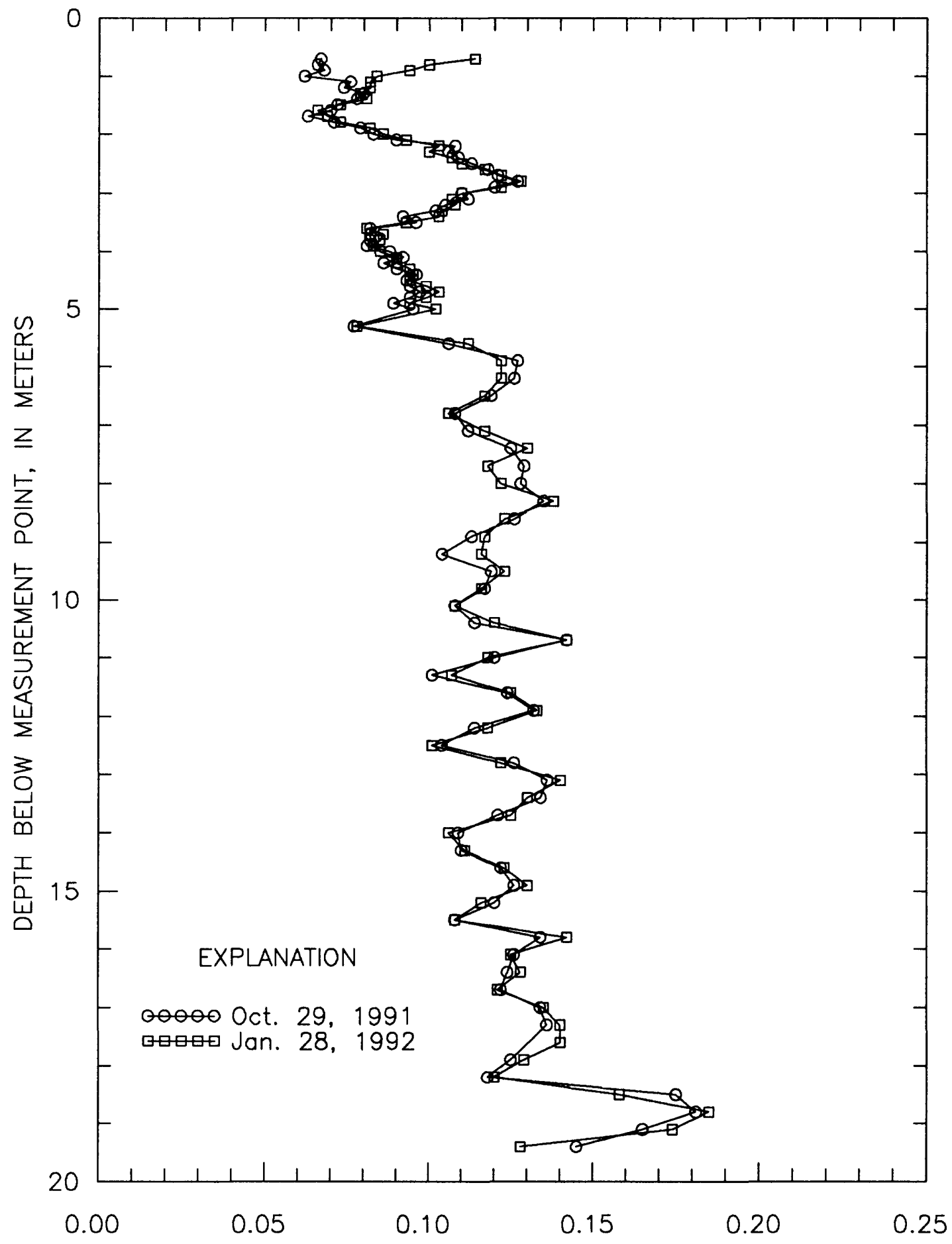

PRELIMINARY COMPUTED VOLUMETRIC WATER CONTENT, IN CUBIC CENTIMETER PER CUBIC CENTIMETER

Figure 11. Preliminary computed volumetric water-content profiles for UE-29 UZN \#92 for Oct. 29, 1991 and Jan. 28, 1992. 


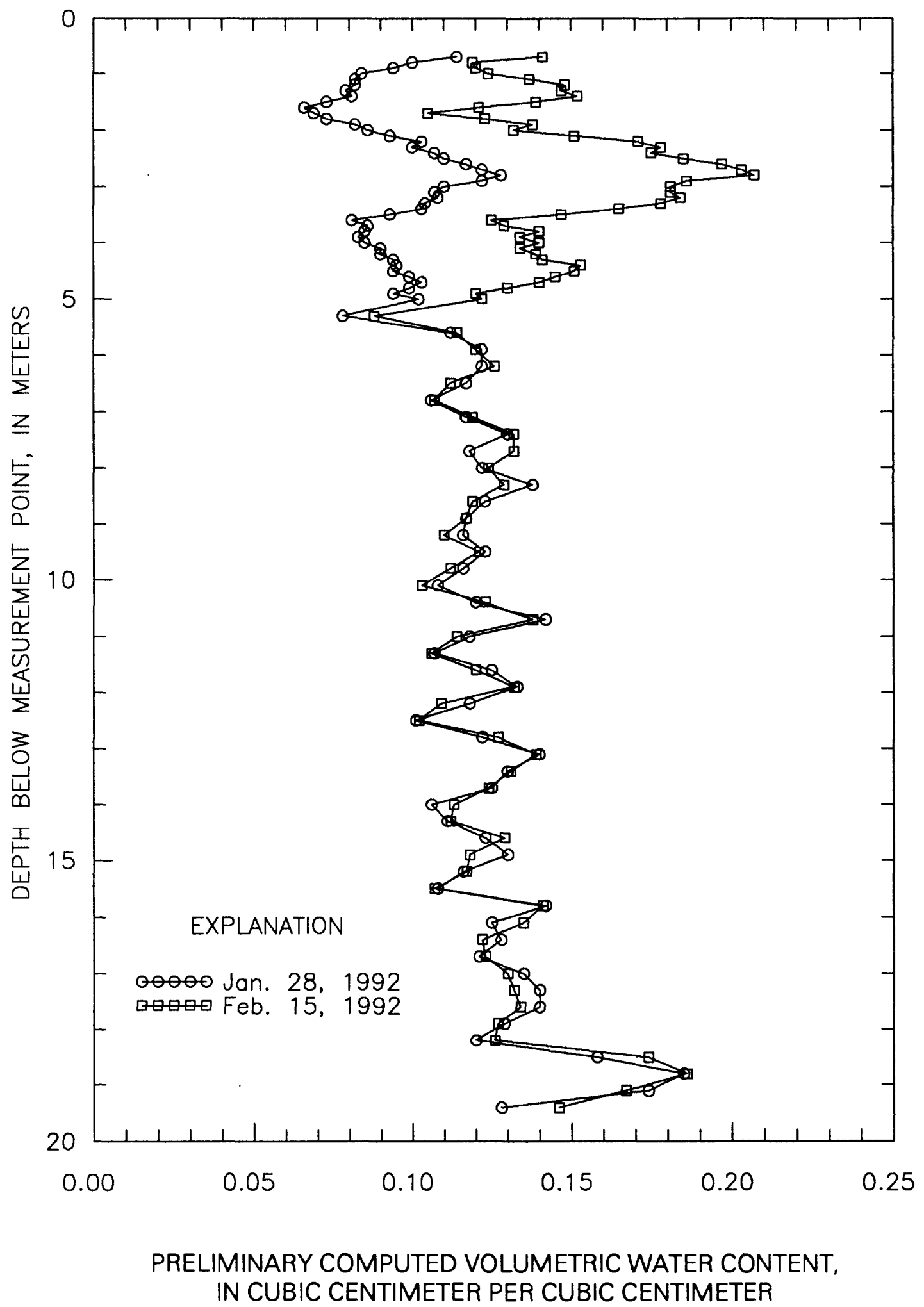

Figure 12. Preliminary computed volumetric water-content profiles for UE-29 UZN \#92 for Jan. 28, 1992 and Feb. 15, 1992. 
15 to March 11, the profile only had minor changes in the vertical water content (fig. 13). From March 11 to May 7, the profile decreased from 0.7 to $2.9 \mathrm{~m}$ and increased from 3.9 to $5.9 \mathrm{~m}$ (fig. 14). From May 7 to August 26, the profile decreased from 0.7 to $5.3 \mathrm{~m}$ (fig. 15). All profiles throughout the $1992 \mathrm{WY}$ did not show any appreciable differences below $5.9 \mathrm{~m}$.

\section{DEPTH-TO-WATER DATA}

Depth-to-water measurements were made in five wells, UE-29 a\# I, UE-29 a\#2, J-13, J-12, and JF-3, and one neutron-access borehole, UE-29 UZN \#91, during the 1992 WY. These wells and the neutron-access borehole are either in or near Fortymile Wash. Depthto-water measurements for J-12, J-13, and JF-3 were collected by other hydrologic studies in the Yucca Mountain Project and will not be reported in this report. JF-3 was drilled and completed during the 1992 WY. Water from aquifer testing in JF-3 was discharged during the WY into the Fortymile Wash channel near the well.

A measurement point was established at each well so successive depth-to-water measurements could be compared (table 6-8). The UE-29 a\#1 measurement point is a scribed point on the top of the well cover, approximately $0.09 \mathrm{~m}$ above land surface. The UE29 a\#2 measurement point is a scribed point on the well cover, approximately $0.1 \mathrm{~m}$ above the land surface. The UE-29 UZN \#91 measurement point is the top of the well casing with the cover removed, approximately $0.9 \mathrm{~m}$ above the land surface. The land surface around UE-29 UZN \#91 is not stable due to erosion and deposition of stream sediments in the channel. Measurement point elevations are not known to an adequate accuracy so the depth-to-water measurements were not converted to an elevation with reference to mean sea level.

The measurements were made with a hand-held steel tape, an electric tape, or both. Both the steel tape and the electric tape use feet as a measurement scale. The steel tape measurements were made by lowering a chalked steel tape into the well and holding at a known depth on the tape. When the tape was removed from the well, the water cut was read. The water cut is the portion of the tape wetted by water in the well. Subtraction of the water cut from the hold is the depth to water for the well below the measurement point at the measurement time. The electric tape measurements were made by lowering the probe in the well until the contacts in the probe just touched the water. Depth to water could be read directly from markings on the electric tape. When both measurement techniques were used, the steel tape was the method used to report the depth-to-water measurement. Depth-to-water mea- surements were converted from feet to meters for reporting purposes.

Depth to water decreased after the February and March streamflow events in all three wells, indicating water levels rose. Water levels rose in UE-29 a\#2 and UE-29 UZN \#91 after the June 29 earthquake, but declined in UE-29 a\#1. The measuring frequency was varied to document changes in the water levels (fig. 16-18). Water could be heard dripping in well UE-29 a\#1 on April 2. Wells UE-29 a\#1 and a\#2 are only $10 \mathrm{~m}$ apart and have depth-to-water measurements that are generally $3 \mathrm{~m}$ different, with UE-29 a\# 1 having the smaller depth to water. This is because the wells are open to different intervals of the geologic strata. The depth to the open intervals of the wells are listed in table 3. Well UE-29 a\#2 is open to the deepest interval of the three wells in the Pah Canyon area.

The highest water level in UE-29 a\#1 was on April 16, when a depth to water of $25.46 \mathrm{~m}$ was measured. The lowest water level was on September 25 when a depth to water of $27.02 \mathrm{~m}$ was measured. The observed range in water level was $1.56 \mathrm{~m}$ for the water year. The highest water level measured in March was on March 2, nineteen days after the February 12 streamflow event. The highest water level measured in April was on April 16, sixteen days after the March 31 streamflow event. The water level declined $1.46 \mathrm{~m}$ during June 22 to 29 , coinciding with the magnitude 5.6 earthquake at Little Skull Mountain on June 29, $27 \mathrm{~km}$ to the southwest.

The highest water level in UE-29 a\#2 was on April 20 when a depth to water of $28.32 \mathrm{~m}$ was measured. The lowest water level was on January 13 when a depth to water of $29.33 \mathrm{~m}$ was measured. The observed range in water level was $1.01 \mathrm{~m}$ for the water year. The highest water level measured in March was on March 2, nineteen days after the February 12 streamflow event. The highest water level measured in April was on April 20, twenty days after the March 31 streamflow event. The water level rose $0.20 \mathrm{~m}$ during June 22 to 29, coinciding with the Little Skull Mountain earthquake on June 29.

The highest water levels in UE-29 UZN \#91 were on April 30, July 1 and 2, when a depth to water of $16.93 \mathrm{~m}$ was measured. The lowest water level was on January 13, when a depth to water of $17.59 \mathrm{~m}$ was measured. The observed range in water level was $0.66 \mathrm{~m}$ for the water year. The highest water level measured in March was during the period March 16 to 30, thirty-three days after the February 12 streamflow event. The highest water level measured in April was on April 30, thirty days after the March 31 streamflow event. The water level rose $0.15 \mathrm{~m}$ during June 22 to 


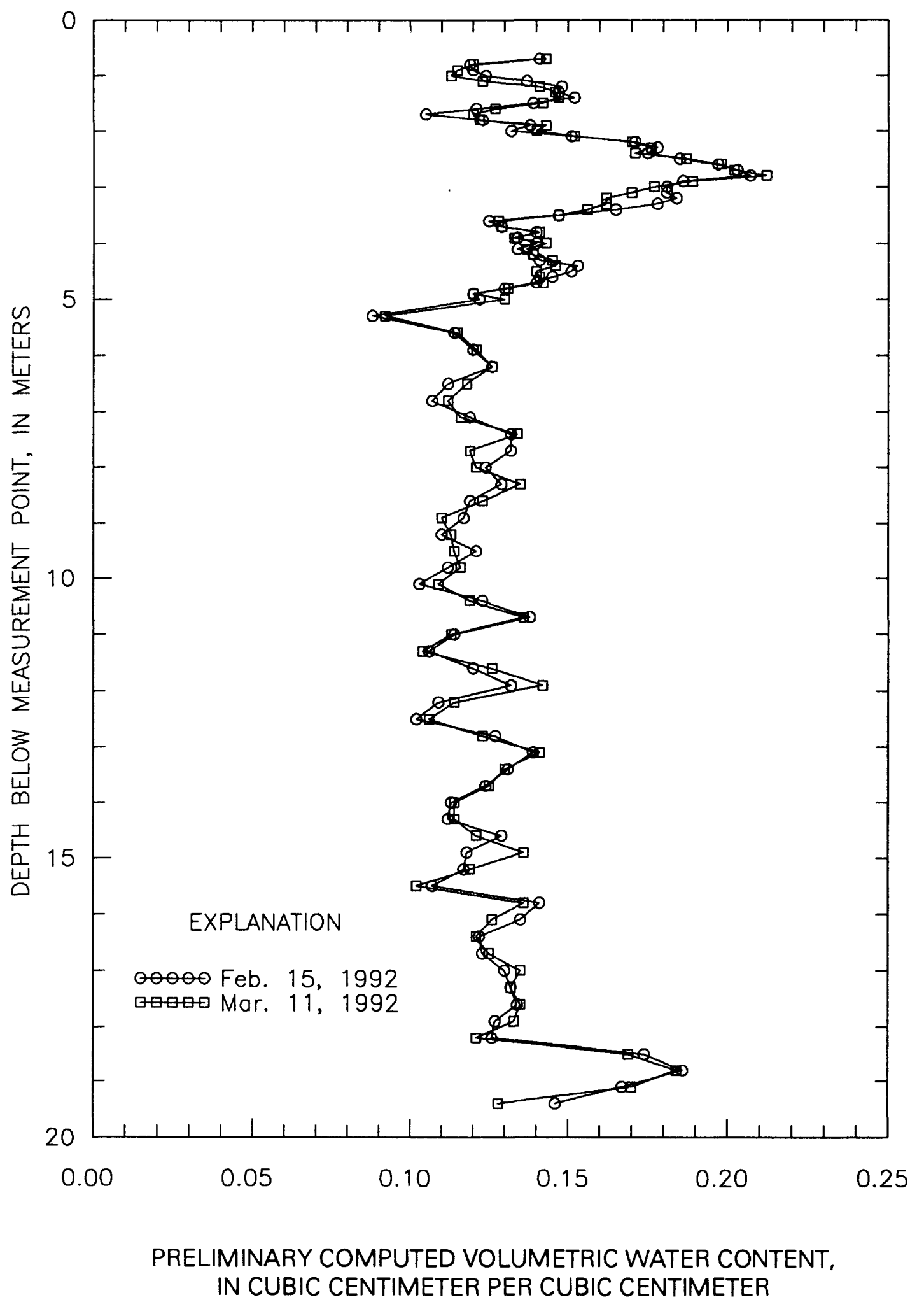

Figure 13. Preliminary computed volumetric water-content profiles for UE-29 UZN \#92 for Feb. 15, 1992 and Mar. 11, 1992. 


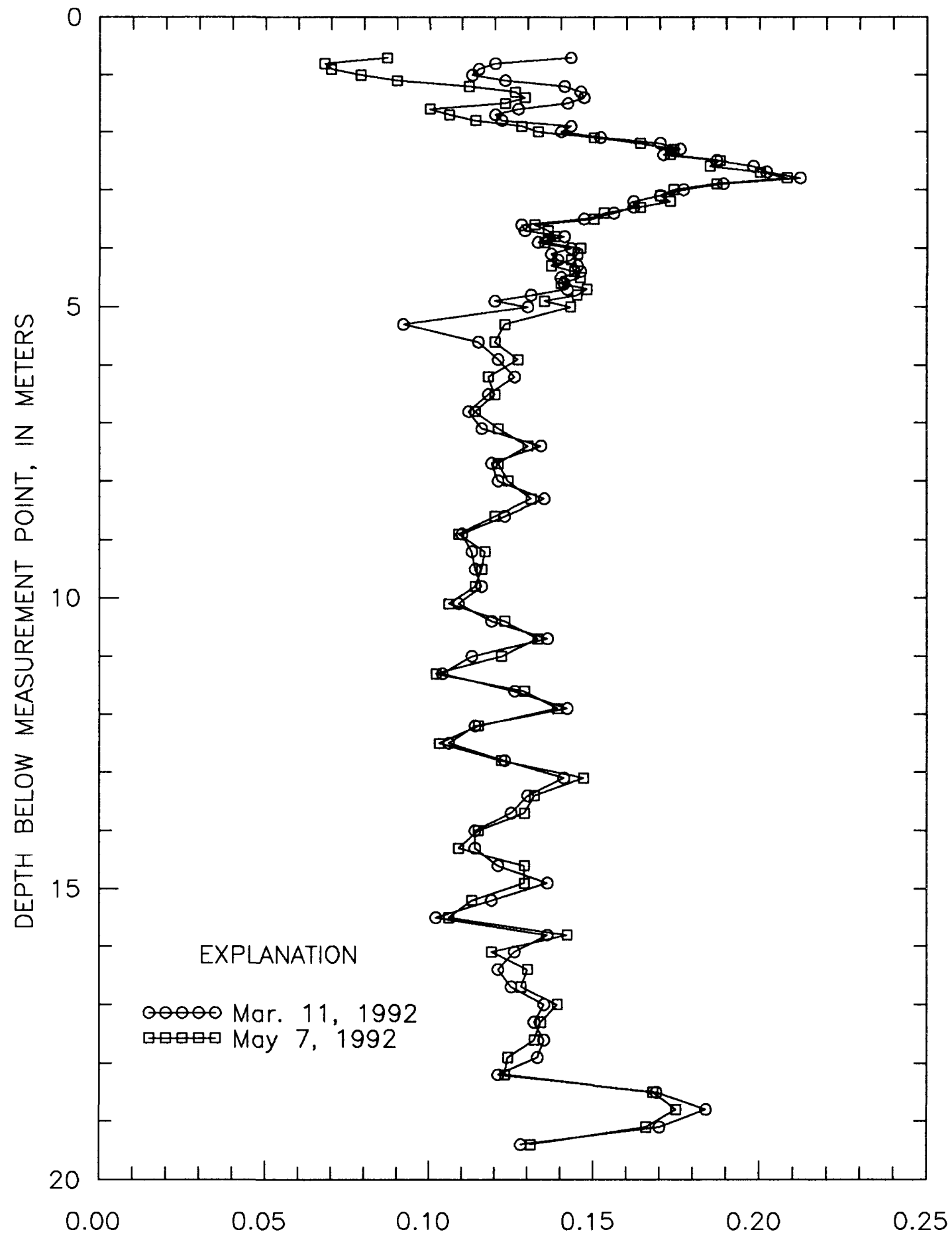

PRELIMINARY COMPUTED VOLUMETRIC WATER CONTENT, IN CUBIC CENTIMETER PER CUBIC CENTIMETER

Figure 14. Preliminary computed volumetric water-content profiles for UE-29 UZN \#92 for Mar. 11, 1992 and May 7, 1992. 


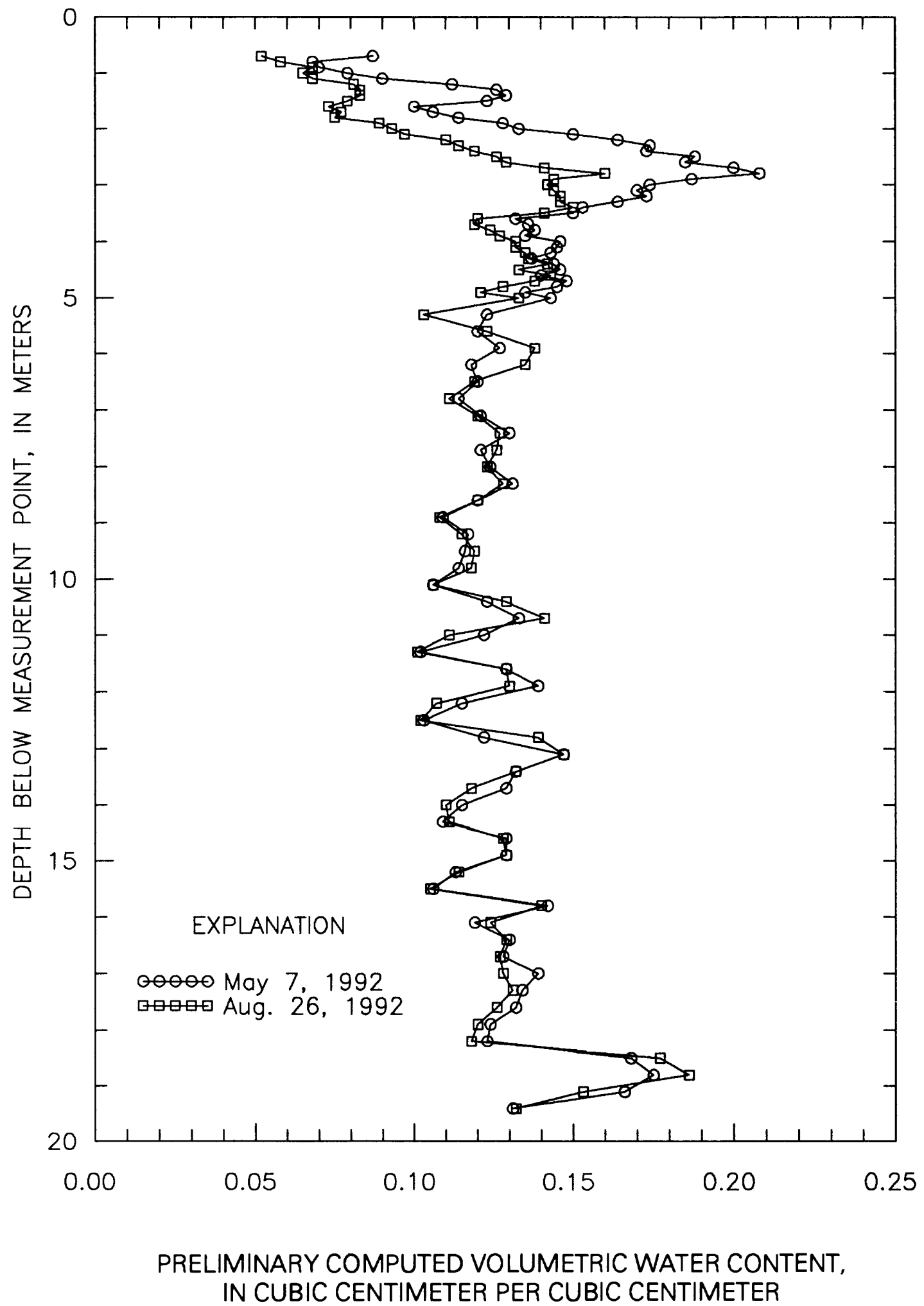

Figure 15. Preliminary computed volumetric water-content profiles for UE-29 UZN \#92 for May 7, 1992 and Aug. 26, 1992. 
Table 6. Depth-to-water measurements in UE-29 a\#1

[m, meter; S, steel tape; E, electric tape]

\begin{tabular}{|c|c|c|c|c|c|c|c|}
\hline Date & Time & $\begin{array}{l}\text { Depth to water } \\
\text { below } \\
\text { measuring } \\
\text { point } \\
\text { (m) }\end{array}$ & Method & Date & Time & $\begin{array}{l}\text { Depth to water } \\
\text { below } \\
\text { measuring } \\
\text { point } \\
\text { (m) }\end{array}$ & Method \\
\hline Jan. 13, 1992 & 1128 & 26.81 & $S$ & May 29,1992 & 1346 & 25.78 & $\bar{E}$ \\
\hline Feb. 25, 1992 & 1024 & 25.62 & $S$ & June 9, 1992 & 1447 & 25.87 & E \\
\hline Mar. 2, 1992 & 1345 & 25.58 & E & June 15,1992 & 1043 & 25.90 & E \\
\hline Mar. 4, 1992 & 1440 & 25.61 & $S$ & June 22, 1992 & 1119 & 25.94 & E \\
\hline Mar. 5, 1992 & 1308 & 25.63 & E & June 29, 1992 & 1029 & 26.48 & $\mathrm{E}$ \\
\hline Mar. 6, 1992 & 1253 & 25.63 & E & June 30, 1992 & 1020 & 26.50 & $\mathrm{E}$ \\
\hline Mar. 9, 1992 & 1045 & 25.67 & E & July 1, 1992 & 1135 & 26.52 & $\mathrm{E}$ \\
\hline Mar. 11, 1992 & 1439 & 25.70 & $\mathrm{E}$ & July 2,1992 & 0942 & 26.55 & E \\
\hline Mar. 13, 1992 & 1033 & 25.73 & E & July 6, 1992 & 0928 & 26.59 & E \\
\hline Mar. 16, 1992 & 1342 & 25.73 & E & July 9,1992 & 1004 & 26.64 & E \\
\hline Mar. 23, 1992 & 0947 & 25.83 & E & July 13,1992 & 0947 & 26.66 & $\mathrm{E}$ \\
\hline Mar. 30, 1992 & 1143 & 25.90 & $\mathrm{E}$ & July 16,1992 & 1131 & 26.67 & $\mathrm{E}$ \\
\hline Mar. 31, 1992 & 1026 & 25.88 & E & July 27,1992 & 1123 & 26.74 & E \\
\hline Apr. 2, 1992 & 1253 & 25.87 & $\mathrm{E}$ & Aug. 3, 1992 & 1358 & 26.77 & $\mathrm{E}$ \\
\hline Apr. 8, 1992 & 1208 & 25.57 & $\mathrm{E}$ & Aug. 10, 1992 & 1152 & 26.82 & $\mathrm{E}$ \\
\hline Apr. 16, 1992 & 1112 & 25.46 & $\mathrm{E}$ & Aug. 17, 1992 & 1106 & 26.86 & $\mathrm{E}$ \\
\hline Apr. 20, 1992 & 1122 & 25.48 & $\mathrm{E}$ & Aug. 26, 1992 & 1213 & 26.93 & $S$ \\
\hline Apr. 23, 1992 & 1038 & 25.50 & $\mathrm{E}$ & Sep. 9, 1992 & 1045 & 26.97 & $S$ \\
\hline Apr. 27, 1992 & 1117 & 25.55 & $\mathrm{E}$ & Sep. 15, 1992 & 0955 & 26.97 & $\mathbf{S}$ \\
\hline Apr. 30, 1992 & 1137 & 25.53 & $\mathrm{E}$ & Sep. 25, 1992 & 1107 & 27.02 & E \\
\hline May 4, 1992 & 1310 & 25.59 & E & & & & \\
\hline May 7, 1992 & 1159 & 25.62 & E & & & & \\
\hline May 18, 1992 & 1050 & 25.74 & E & & & & \\
\hline May 21, 1992 & 1115 & 25.74 & E & & & & \\
\hline May 26, 1992 & 1146 & 25.75 & E & & & & \\
\hline
\end{tabular}


Table 7. Depth-to-water measurements in UE-29 a\#2

[m, meter; S, steel tape; E, electric tape]

\begin{tabular}{|c|c|c|c|c|c|c|c|}
\hline Date & Time & $\begin{array}{l}\text { Depth to water } \\
\text { below } \\
\text { measuring } \\
\text { point } \\
\text { (m) }\end{array}$ & Method & Date & Time & $\begin{array}{l}\text { Depth to water } \\
\text { below } \\
\text { measuring } \\
\text { point } \\
\text { (m) }\end{array}$ & Method \\
\hline Jan. 13, 1992 & 1113 & 29.33 & $S$ & May 29,1992 & 1343 & 28.50 & $\bar{E}$ \\
\hline Feb. 25, 1992 & 1005 & 28.67 & $S$ & June 9,1992 & 1445 & 28.54 & E \\
\hline Mar. 2, 1992 & 1340 & 28.51 & $\mathrm{E}$ & June 15,1992 & 1040 & 28.59 & E \\
\hline Mar. 4, 1992 & 1434 & 28.52 & $\mathbf{S}$ & June 22, 1992 & 1116 & 28.62 & E \\
\hline Mar. 5, 1992 & 1305 & 28.54 & E & June 29, 1992 & 1027 & 28.42 & E \\
\hline Mar. 6, 1992 & 1250 & 28.55 & $\mathrm{E}$ & June 30,1992 & 1017 & 28.37 & $\mathrm{E}$ \\
\hline Mar. 9, 1992 & 1043 & 28.57 & $\mathrm{E}$ & July 1, 1992 & 1133 & 28.39 & E \\
\hline Mar. 11, 1992 & 1437 & 28.56 & $\mathbf{E}$ & July 2,1992 & 0940 & 28.38 & $\mathbf{E}$ \\
\hline Mar. 13, 1992 & 1031 & 28.57 & E & July 6,1992 & 0926 & 28.41 & E \\
\hline Mar. 16, 1992 & 1340 & 28.54 & E & July 9,1992 & 1002 & 28.46 & $\mathbf{E}$ \\
\hline Mar. 23, 1992 & 0945 & 28.62 & $\mathbf{E}$ & July 13,1992 & 0936 & 28.47 & $\mathbf{E}$ \\
\hline Mar. 30, 1992 & 1140 & 28.64 & E & July 16,1992 & 1129 & 28.48 & $\mathbf{E}$ \\
\hline Mar. 31, 1992 & 1024 & 28.65 & $\mathrm{E}$ & July 27,1992 & 1121 & 28.57 & $\mathbf{E}$ \\
\hline Apr. 2, 1992 & 1250 & 28.61 & $\mathbf{E}$ & Aug. 3, 1992 & 1355 & 28.55 & $\mathbf{E}$ \\
\hline Apr. 8, 1992 & 1204 & 28.41 & E & Aug. 10, 1992 & 1150 & 28.63 & E \\
\hline Apr. 16,1992 & 1110 & 28.34 & E & Aug. 17, 1992 & 1100 & 28.65 & $\mathbf{E}$ \\
\hline Apr. 20,1992 & 1120 & 28.32 & E & Aug. 26, 1992 & 1206 & 28.72 & $S$ \\
\hline Apr. 23, 1992 & 1035 & 28.35 & E & Sep. 9, 1992 & 1036 & 28.75 & $S$ \\
\hline Apr. 27, 1992 & 1114 & 28.36 & E & Sep. 15,1992 & 0950 & 28.74 & $S$ \\
\hline Apr. 30,1992 & 1135 & 28.35 & $\mathbf{E}$ & Sep. 25,1992 & 1104 & 28.83 & E \\
\hline May 4, 1992 & 1308 & 28.40 & $\mathbf{E}$ & & & & \\
\hline May 7, 1992 & 1157 & 28.41 & E & & & & \\
\hline May 18,1992 & 1048 & 28.48 & E & & & & \\
\hline May 21, 1992 & 1112 & 28.46 & E & & & & \\
\hline May 26, 1992 & 1142 & 28.48 & $\mathrm{E}$ & & & & \\
\hline
\end{tabular}


Table 8. Depth-to-water measurements in UE-29 UZN \#91

[m, meter; S, steel tape; E, electric tape]

\begin{tabular}{|c|c|c|c|c|c|c|c|}
\hline Date & Time & $\begin{array}{l}\text { Depth to water } \\
\text { below } \\
\text { measuring } \\
\text { point } \\
\text { (m) }\end{array}$ & Method & Date & Time & $\begin{array}{l}\text { Depth to water } \\
\text { below } \\
\text { measuring } \\
\text { point } \\
\text { (m) }\end{array}$ & Method \\
\hline Jan. 13, 1992 & 1149 & 17.59 & $S$ & May 18,1992 & 1037 & 16.98 & $\bar{E}$ \\
\hline Jan. 28, 1992 & 1143 & 17.58 & $S$ & May 21, 1992 & 1102 & 16.98 & $S$ \\
\hline Feb. 21, 1992 & 1245 & 17.31 & $s$ & May 26, 1992 & 1130 & 17.00 & $S$ \\
\hline Feb. 25, 1992 & 1041 & 17.25 & $s$ & May 29, 1992 & 1329 & 17.00 & $s$ \\
\hline Feb. 25, 1992 & 1455 & 17.22 & $S$ & June 9, 1992 & 1440 & 17.03 & $S$ \\
\hline Mar. 2, 1992 & 1245 & 17.14 & $S$ & June 15,1992 & 1028 & 17.05 & $S$ \\
\hline Mar. 4, 1992 & 1418 & 17.12 & $S$ & June 22, 1992 & 1023 & 17.08 & $S$ \\
\hline Mar. 5, 1992 & 1234 & 17.12 & $S$ & June 29, 1992 & 1020 & 17.00 & $S$ \\
\hline Mar. 6, 1992 & 1151 & 17.11 & $S$ & June 30,1992 & 1009 & 16.94 & $S$ \\
\hline Mar. 9, 1992 & 1031 & 17.11 & $S$ & July 1, 1992 & 1126 & 16.93 & $S$ \\
\hline Mar. 11, 1992 & 1348 & 17.10 & $S$ & July 2, 1992 & 0930 & 16.93 & $S$ \\
\hline Mar. 13, 1992 & 1023 & 17.10 & $s$ & July 6, 1992 & 0919 & 16.95 & $S$ \\
\hline Mar. 16, 1992 & 1330 & 17.09 & $s$ & July 9, 1992 & 0955 & 16.97 & $S$ \\
\hline Mar. 23, 1992 & 0935 & 17.09 & $S$ & July 13,1992 & 0920 & 16.99 & $S$ \\
\hline Mar. 30, 1992 & 1130 & 17.09 & $S$ & July 16,1992 & 1120 & 17.00 & $S$ \\
\hline Mar. 31, 1992 & 1017 & 17.10 & $\mathbf{E}$ & July 27,1992 & 1030 & 17.05 & $S$ \\
\hline Apr. 2, 1992 & 1135 & 17.09 & $S$ & Aug. 3, 1992 & 1343 & 17.07 & $S$ \\
\hline Apr. 8, 1992 & 1111 & 17.02 & $S$ & Aug. 10, 1992 & 1139 & 17.10 & $S$ \\
\hline Apr. 16, 1992 & 1100 & 16.96 & $S$ & Aug. 17, 1992 & 1050 & 17.12 & $S$ \\
\hline Apr. 20, 1992 & 1111 & 16.94 & $S$ & Aug. 26, 1992 & 1045 & 17.15 & $S$ \\
\hline Apr. 23, 1992 & 1024 & 16.94 & $S$ & Sep. 9, 1992 & 1024 & 17.18 & $S$ \\
\hline Apr. 27, 1992 & 1104 & 16.94 & $S$ & Sep. 15, 1992 & 0939 & 17.20 & $S$ \\
\hline Apr. 30, 1992 & 1125 & 16.93 & $S$ & Sep. 25, 1992 & 1052 & 17.22 & $S$ \\
\hline May 4, 1992 & 1245 & 16.95 & $S$ & & & & \\
\hline May 7, 1992 & 1100 & 16.95 & $\mathbf{S}$ & & & & \\
\hline
\end{tabular}




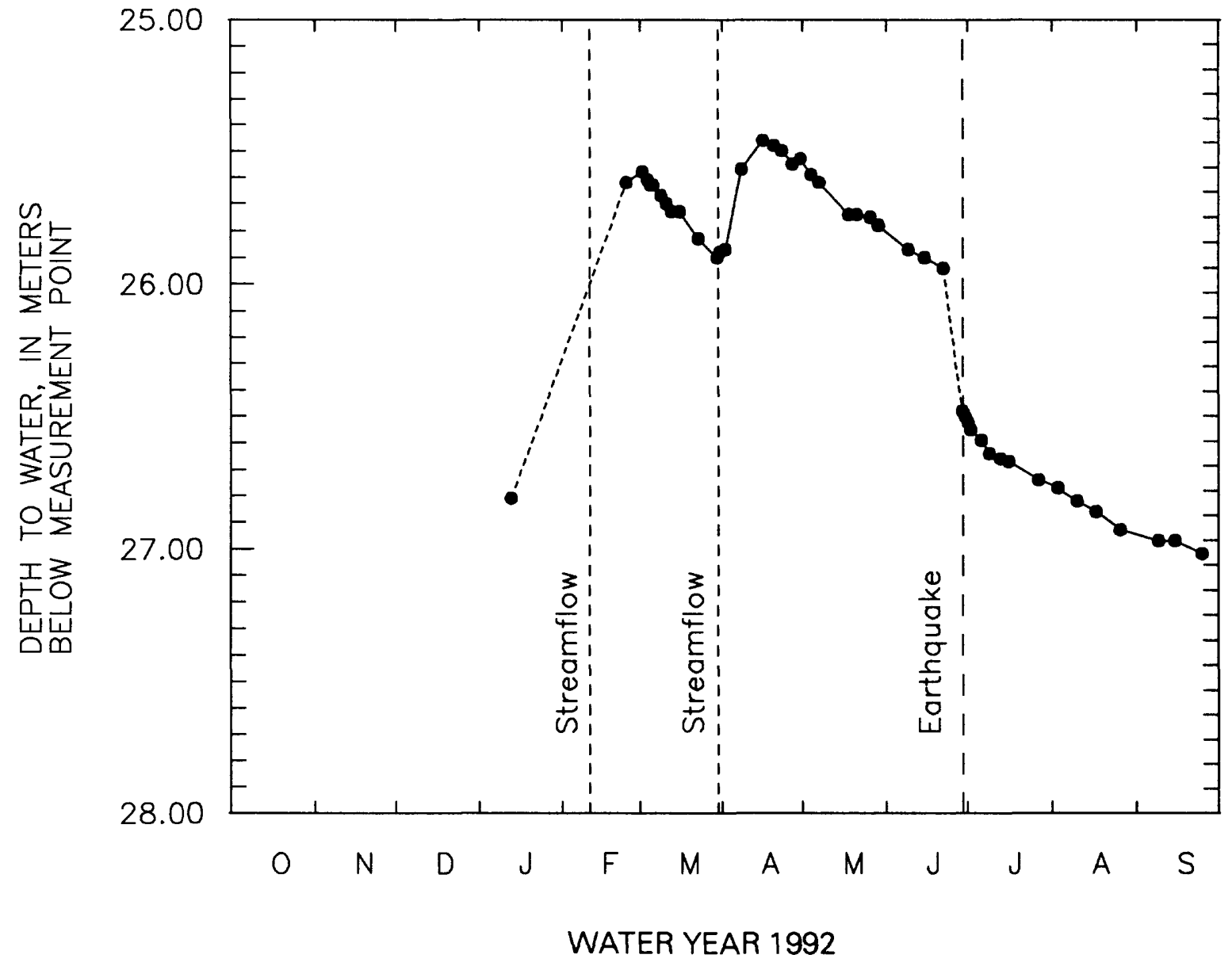

Figure 16. Depth-to-water measurements in UE-29 a\#1. 


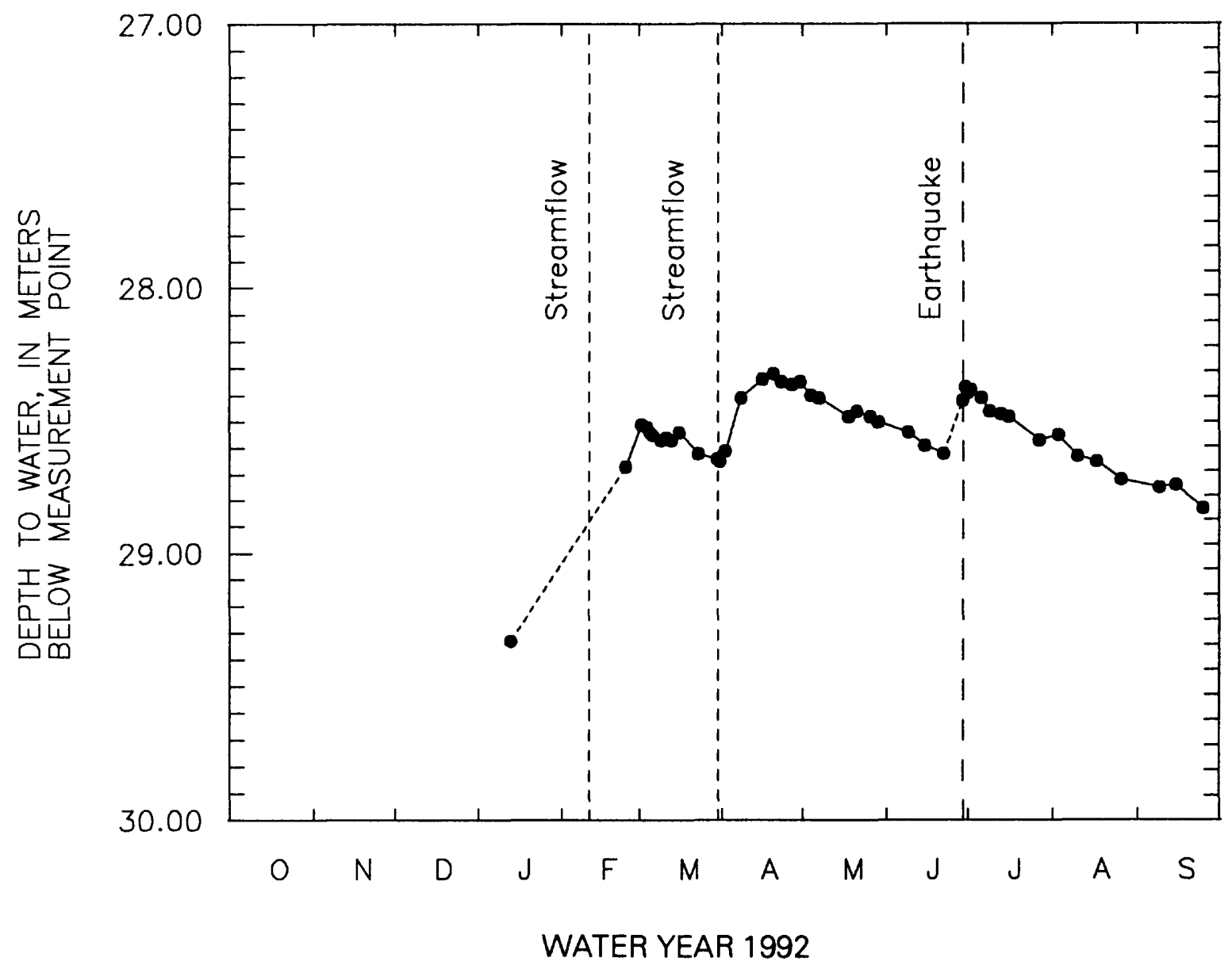

Figure 17. Depth-to-water measurements in UE-29 a\#2. 


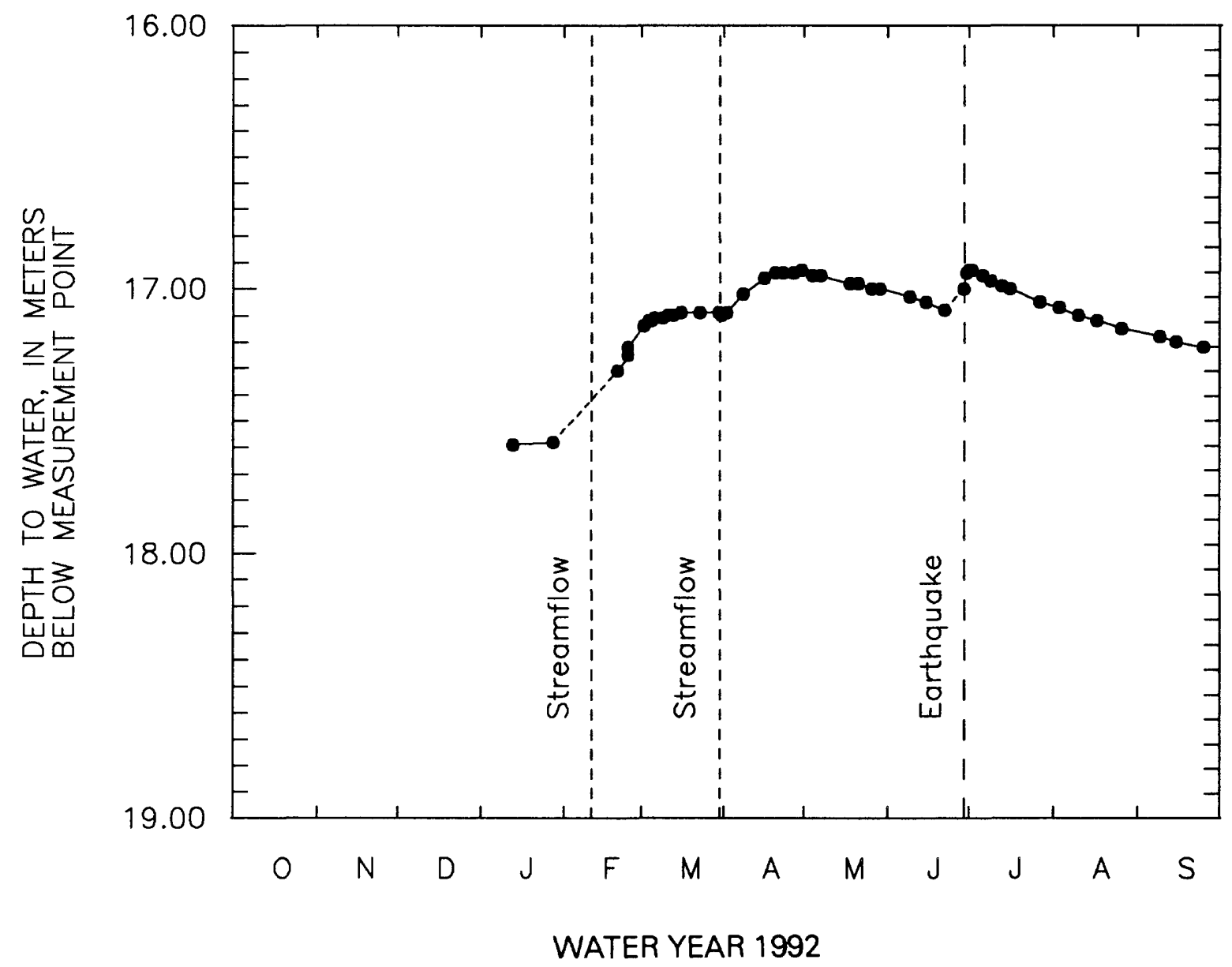

Figure 18. Depth-to-water measurements in UE-29 UZN \#91. 
July 1 , coinciding with the Little Skull Mountain earthquake on June 29.

\section{QUALITY ASSURANCE}

Data in this report will be used in the evaluation of the suitability of the Yucca Mountain site for a potential high-level nuclear-waste repository. Confidence in the reliability of collection, processing, and reporting of the hydrologic data is necessary so the data may be used with confidence to assess the expected performance of the potential repository. A qualityassurance program has been implemented to support the reliability of the data. The precipitation data collected with the rain wedges reported in this report were not collected under a quality-assurance program. The neutron-logging and water-level data were all collected under a quality-assurance program.

The neutron-logging profiles and water-level measurements were obtained by methods described by formal technical procedures as required by the U.S. Geological Survey Yucca Mountain Project qualityassurance program. The technical procedures included tests and adjustments done during the measuring operation to ensure the equipment was operating properly and the expected precision and accuracy were attained. For example, the technical procedure to neutron log a borehole specified how to perform standardization tests, $\log$ the borehole, and process the data.

\section{HYDROLOGIC SUMMARY}

From October to late December 1991, there was a small amount of precipitation in the Fortymile Wash drainage basin. No streamflow was observed, and neutron logging indicated no precipitation was infiltrating. From late December until early April, 1992, precipitation occurred from a series of regional storms. Localized streamflow occurred in the Pah Canyon, Delirium Canyon, and Yucca Wash drainage basins of the Fortymile Wash drainage basin with some streamflow going into the main Fortymile Wash channel during February 12-14 and March 31. The streamflow infiltrated into the streambed sediments to a depth of 5 meters at two neutron-access borehole locations. The moisture from the streamflow events then redistributed when moisture contents in the upper $5 \mathrm{~m}$ of the boreholes decreased, and from 5.0 to $5.9 \mathrm{~m}$ increased. Ground-water levels rose at wells UE-29 a\#1 and UE-29 a\#2 and neutron-access borehole UE-29 UZN \#91 after each streamflow event for approximately two weeks, and then began a steady decline.

From late April to September 1992, there were only small amounts of precipitation, and no streamflow was observed. The moisture in the vertical profiles continued to redistribute from April to May, when moisture contents in the upper $5 \mathrm{~m}$ of the borehole decreased, and from 5.0 to $5.9 \mathrm{~m}$ increased. From May to September, the moisture content of the entire vertical profiles decreased. Ground-water levels decreased from April to September, except for a shift coinciding with the June 29 earthquake at Little Skull Mountain.

\section{REFERENCES CITED}

Benson, L., and Klieforth, H., 1989, Stable isotopes in precipitation and ground water in the Yucca Mountain region, southern Nevada: Paleoclimate implications: in Aspects of climate variability in the Pacific and Western Americas, edited by Peterson, D.H.: American Geophysical Union Geophysical Monograph 55, p. 41-59. (NNA.910617.0057)

Claassen, H.C., 1985, Sources and mechanisms of recharge for ground water in the West-Central Amargosa Desert, Nevada—a geochemical interpretation: U.S. Geological Survey Professional Paper 712-F, 31 p.

(NNA.900124.0031)

Czarnecki, J.B., and Waddell, R.K., 1984, Finite-element simulation of ground-water flow in the vicinity of Yucca Mountain, Nevada-California: U.S. Geological Survey Water-Resources Investigations Report 84-4349, 38 p. (NNA.870407.0173)

Gardner, W.H., 1986, Water Content: in Methods of soil analysis, part 1, Physical and Mineralogical Methods, edited by Klute, Arnold: Agronomy Monograph no. 9 (2nd Edition), p. 493-544. (NNA.900208.0104)

Gemmel, J.M., 1990, Water levels in periodically measured wells in the Yucca Mountain area, Nevada, 1988: U.S. Geological Survey Open-File Report 90-113, 47 p. (NNA.900221.0001)

Huber, N.K., 1988, Late Cenozoic evolution of the upper Amargosa River drainage system, southwestern Great Basin, Nevada and California: U.S. Geological Survey Open-File Report 87-617, 26 p. (NNA.880525.0028)

Kane, T.G., Bauer, D.J., and Martinez, C.M., 1994, Streamflow and selected precipitation data for Yucca Mountain region, southern Nevada and eastern California, water years 1986-90: U.S. Geological Survey Open-File Report 94-312, 118 p. (NNA.940621.0004)

Luckey, R.R., Lobmeyer, D.H., and Burkhardt, D.J., 1993, Water levels in continuously monitored wells in the Yucca Mountain area, Nevada, 1985-88: U.S. Geological Survey Open-File Report 91-493, 252 p.

(NNA.910611.0014)

Moore, J.E., 1961, Records of wells, test holes, and springs in the Nevada Test Site and surrounding area: U.S. Geological Survey Open-File Report TEI-781, 22 p. (NNA.901026.0052) 
Moore, J.E., 1962, Selected logs and drilling records of wells and test holes drilled at the Nevada Test Site prior to 1960: U.S. Geological Survey Open-File Report TEI-804, 54 p. (MOL.19941208.0007)

O'Brien, G.M., 1991, Water levels in periodically measured wells in the Yucca Mountain area, Nevada, 1989: U.S. Geological Survey Open-File Report 91-178, 51 p. (NNA.910708.0041)

Pabst, M.E., Beck, D.A., Glancy, P.A., and Johnson, J.A., 1993, Streamflow and selected precipitation data for Yucca Mountain and vicinity, Nye County, Nevada, water years 1983-85: U.S. Geological Survey OpenFile Report 93-438, 66 p. (NNA.931019.0043)

Robison, J.H., 1984, Ground-water level data and preliminary potentiometric-surface maps, Yucca Mountain and vicinity, Nye County, Nevada, 8 p.

(NNA.870519.0096)

Robison, J.H., Stephens, D.M., Luckey, R.R., and Baldwin, D.A., 1988, Water levels in periodically measured wells in the Yucca Mountain area, Nevada, 1981-87: U.S. Geological Survey Open-File Report 88-468, 132 p. (NNA.890306.0113)

Squires, R.R., and Young, R.L., 1984, Flood potential of Fortymile Wash and its principal southwestern tributaries, Nevada Test Site, southern Nevada: U.S. Geological Survey Water-Resources Investigations Report 83-4001, 33 p. (NNA.890511.0110)

Thordarson, William, Young, R.A., and Winograd, I.J., 1967, Records of wells and test holes in the Nevada Test Site and vicinity: U.S. Geological Survey Open-File Report TEI-872, 26 p. (HQS.880517.1851)

U.S. Department of Energy, 1988, Site characterization plan, Yucca Mountain site, Nevada research and development area, Nevada: U.S. Department of Energy Report
DOE RW/0199, $8 \mathrm{v}$, various pagination. (HQS.881201.002)

Waddell, R.K., 1982, Two-dimensional, steady-state model of ground-water flow, Nevada Test Site and vicinity, Nevada-California: U.S. Geological Survey WaterResources Investigations Report 82-4085, 72 p. (NNA.870518.0055) 1984, Hydrologic and drill-hole data for test wells UE-29a\#1 and UE-29a\#2, Fortymile Canyon, Nevada Test Site: U.S. Geological Survey Open-File Report 84-142, 25 p. (NNA.870406.0055)

Waddell, R.K., Robison, J.H., and Blankennagel, R.K., 1984, Hydrology of Yucca Mountain and vicinity, Nevada-California-investigative results through mid1983: U.S. Geological Survey Water-Resources Investigations Report 84-4267, 72 p. (NNA.900618.0074)

White, A.F., and Chuma, N.J., 1987, Carbon and isotopic mass balance models of Oasis Valley-Fortymile Canyon groundwater basin, southern Nevada: Water Resources Research, v. 23, no. 4, p. 571-582. (MOL.19941208.0004)

Winograd, I.J., and Thordarson, William, 1975, Hydrogeologic and hydrochemical framework, south-central Great Basin, Nevada-California, with special reference to the Nevada Test Site: U.S. Geological Survey Professional Paper 712-C, 126 p. (NNA.870406.0201)

Young, R.A., 1972, Water supply for the nuclear rocket development station at the U.S. Atomic Energy Commission's Nevada Test Site: U.S. Geological Survey Water-Supply Paper 1938, 19 p. (NNA.870519.0070)

NOTE: Parenthesized numbers following each cited reference are for U.S. Department of Energy OCRWM Records Management purposes only and should not be used when ordering the publication. 